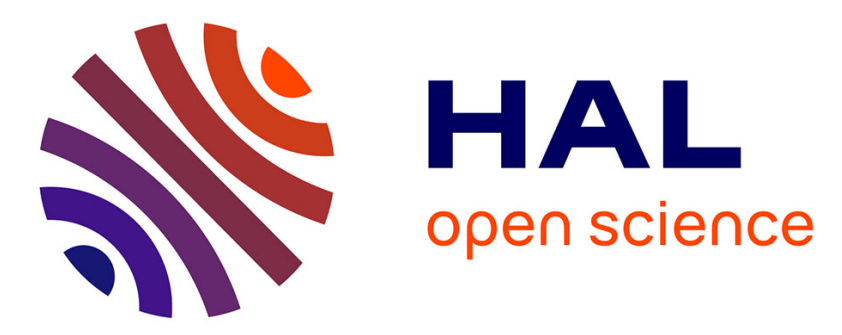

\title{
Thermal decomposition of carbonates in fault zones: Slip-weakening and temperature-limiting effects
}

\author{
J Sulem, Vincent Famin
}

\section{To cite this version:}

J Sulem, Vincent Famin. Thermal decomposition of carbonates in fault zones: Slip-weakening and temperature-limiting effects. Journal of Geophysical Research, 2009, 114 (B3), pp.B03309. 10.1029/2008JB006004 . hal-01386675

\section{HAL Id: hal-01386675 \\ https://hal.science/hal-01386675}

Submitted on 24 Oct 2016

HAL is a multi-disciplinary open access archive for the deposit and dissemination of scientific research documents, whether they are published or not. The documents may come from teaching and research institutions in France or abroad, or from public or private research centers.
L'archive ouverte pluridisciplinaire HAL, est destinée au dépôt et à la diffusion de documents scientifiques de niveau recherche, publiés ou non, émanant des établissements d'enseignement et de recherche français ou étrangers, des laboratoires publics ou privés. 


\title{
Thermal decomposition of carbonates in fault zones: Slip-weakening and temperature-limiting effects
}

\author{
J. Sulem ${ }^{1}$ and V. Famin ${ }^{2}$ \\ Received 11 August 2008; revised 16 December 2008; accepted 13 January 2009; published 28 March 2009.
}

[1] During an earthquake, the heat generated by fault friction may be large enough to activate the devolatilization of minerals forming the fault rocks. In this paper, we model the mechanical effects of calcite thermal decomposition on the slip behavior of a fault zone during an earthquake. To do so, we introduce the coupled effects of calcite volume loss, heat consumption, and $\mathrm{CO}_{2}$ production in the theoretical analysis of shear heating and thermal pressurization of pore fluids. We consider a rapidly deforming shear band consisting of a fluid-saturated carbonate rock. The equations that govern the evolution of pore pressure and temperature inside the band and the mass of emitted $\mathrm{CO}_{2}$ are deduced from the mass and energy balance of the multiphase-saturated medium and from the kinetics of the chemical decomposition of calcite. Numerical simulation of seismic slip at depths of 5 to $8 \mathrm{~km}$ show that decarbonation has two critical consequences on fault slip. First, the endothermic reaction of calcite decomposition limits the coseismic temperature increase to less than $\sim 800^{\circ} \mathrm{C}$ (corresponding to the initiation of the chemical reaction) inside the shear band. Second, the rapid emission of $\mathrm{CO}_{2}$ by decarbonation significantly increases the slip-weakening effect of thermal pressurization. The pore pressure reaches a maximum and then decreases due to the reduction of solid volume, causing a restrengthening of shear stress. Our theoretical study shows, on the example of decarbonation, that the thermal decomposition of minerals is an important slip-weakening process and that a large part of the frictional heat of earthquakes may go into endothermic devolatilization reactions.

Citation: Sulem, J., and V. Famin (2009), Thermal decomposition of carbonates in fault zones: Slip-weakening and temperaturelimiting effects, J. Geophys. Res., 114, B03309, doi:10.1029/2008JB006004.

\section{Introduction}

[2] During the rupture of a fault, an earthquake occurs because the frictional resistance to slip on the fault walls decreases with increasing slip, causing an acceleration of sliding [for a review, see Kanamori and Brodsky, 2004]. To quantify the energy dissipated by an earthquake and assess the hazard of future ruptures, it is critical to understand the mechanics of slip weakening, i.e. how and how much fault friction drops in due course of the rupture. However, our knowledge of slip weakening is still limited, because it results from a complex combination of dynamic, short-lived processes, whose relative importance is difficult to assess quantitatively. Consequently, estimating fault friction and the energy balance of earthquakes is still a major issue in seismology.

[3] Recent theoretical studies have emphasized the role of thermal pore fluid pressurization as an important cause of

${ }^{1}$ CERMES, UR Navier, Ecole des Ponts ParisTech, Universite ParisEst, Marne-la Vallée, France.

${ }^{2}$ Géosciences Réunion (LSTUR), Université de la Réunion, Institut de Physique du Globe de Paris/CNRS, Saint Denis messag, La Réunion, France.

Copyright 2009 by the American Geophysical Union. 0148-0227/09/2008JB006004\$09.00 slip weakening, among other processes such as shear melting, elastohydrodynamic pressurization or silica gel lubrication [McKenzie and Brune, 1972; Lachenbruch, 1980; Melosh, 1996; Brodsky and Kanamori, 2001; Di Toro et al., 2004]. The principle of slip weakening by thermal pressurization is based on the fact that pore fluids trapped inside the fault zone are put under pressure by shear heating, thus inducing a reduction of the effective mean stress, and of the shearing resistance of the fault plane [Lachenbruch, 1980; Mase and Smith, 1985; Andrews, 2002; Wibberley and Shimamoto, 2005; Rempel and Rice, 2006; Rice, 2006; Sulem et al., 2005, 2007]. Those studies rely on the assumption that no fluid is produced nor consumed during seismic slip. There is, however, growing evidence that temperatureinduced decomposition of minerals may be a significant source of fluids in fault rocks [e.g., Han et al., 2007].

[4] In this paper, we investigate the impact of heatinduced mineral destabilization on the frictional properties of a shear zone during seismic slip. Our study focuses on the kinetics of chemical decomposition of calcite (decarbonation) $\mathrm{CaCO}_{3} \rightarrow \mathrm{CaO}+\mathrm{CO}_{2}$ because carbonates are present in every fault zones from the ductile-brittle transition $(\sim 15 \mathrm{~km})$ to the subsurface, and because positive $\mathrm{CO}_{2}$ anomalies are observed in the vicinity of many active crustal faults. To take calcite destabilization and $\mathrm{CO}_{2}$ degassing into account, we introduce the additional com- 
plexity of mineral volume loss and fluid production in the thermal pressurization model.

[5] The equations that govern the evolution of pore pressure and temperature inside the shear zone and the mass of emitted $\mathrm{CO}_{2}$ are deduced from the mass and energy balance of the multiphase-saturated medium and from the kinetics of decarbonation. Our numerical simulations of seismic slip at depths of 5 to $8 \mathrm{~km}$ show that decarbonation has critical consequences on the slip-weakening behavior and heat production of a fault in carbonate rocks, especially for $\mathrm{M}_{\mathrm{w}}>5$ earthquakes.

\section{Previous Work on Thermal Pressurization, Mineral Decomposition, and Porosity Variation}

[6] Important theoretical advances have been recently proposed in the study of thermal weakening of fault during coseismic slip and one can find an extensive literature review on the subject in the work of Rice [2006]. Temperature increase in saturated porous rocks leads to thermal pressurization of the pore fluid due to the discrepancy between the thermal expansion coefficients of the pore fluid and of the solid phase. This increase in the pore fluid pressure induces a reduction of the effective mean stress, and of the shearing resistance of the fault material [Sibson, 1973; Lachenbruch, 1980; Mase and Smith, 1985; Andrews, 2002; Wibberley and Shimamoto, 2005; Rice, 2006; Sulem et al., 2005, 2007]. The presence of clay material in fault zones also affects thermal pressurization as possible collapse of the clay under thermal loading may activate fluid pressurization [Sulem et al., 2004, 2007; Veveakis et al., 2007]. The values of the undrained thermal pressurization coefficient $\Lambda$, defined as the pore pressure increase due to a unit temperature increase in undrained condition, is largely dependent upon the nature of the material, the state of stress, the range of temperature change and the induced damage. In the literature we can find values that differ of two orders of magnitude: In Campanella and Mitchell [1968], different values are found from $0.01 \mathrm{MPa} /{ }^{\circ} \mathrm{C}$ for clay to $0.05 \mathrm{MPa} /{ }^{\circ} \mathrm{C}$ for sandstone. Palciauskas and Domenico [1982] estimate a value of $0.59 \mathrm{MPa} /{ }^{\circ} \mathrm{C}$ for Kayenta sandstone. On the basis of Sultan [1997] experimental data on Boom clay, Vardoulakis [2002] estimates this coefficient as $0.06 \mathrm{MPa} /{ }^{\circ} \mathrm{C}$. For a clayey fault gouge extracted at a depth of $760 \mathrm{~m}$ in Aigion fault in the Gulf of Corinth (Greece), the value obtained by Sulem et al. [2004] is $0.1 \mathrm{MPa} /{ }^{\circ} \mathrm{C}$ and for intact rock at great depth, the value given by Lachenbruch $[1980]$ is $1.5 \mathrm{MPa} /{ }^{\circ} \mathrm{C}$. For a mature fault at $7 \mathrm{~km}$ depth at normal stress of 196 $\mathrm{MPa}$, ambient pore pressure of $70 \mathrm{MPa}$, and ambient temperature of $210^{\circ} \mathrm{C}$, Rice [2006] estimates this coefficient as $0.92 \mathrm{MPa} /{ }^{\circ} \mathrm{C}$ in case of intact fault walls and $0.31 \mathrm{MPa} /{ }^{\circ} \mathrm{C}$ in case of damage fault wall. On the basis of an experimental study on a sandstone, Ghabezloo and Sulem [2009] have emphasized the importance of pressure-dependent compressibility of rocks and pressure and temperature dependent compressibility and thermal expansion of pore water on thermal pressurization and have found values between 0.02 and $0.7 \mathrm{MPa} /{ }^{\circ} \mathrm{C}$.

[7] If for simplicity one assumes that the pressurization coefficient does not change with temperature and pore pressure, an analytical solution can be obtained for the evolution of the temperature and of the pore pressure in an infinite long shear band under uniform shear for no heat and fluid transfer [Sulem et al., 2005; Rice, 2006]. This undrained adiabatic limit is applicable as soon as the slip event is sufficiently rapid considering the low permeability and thermal diffusivity of fault materials. This solution shows that the pore pressure increases with the slip displacement from its initial hydrostatic value $P_{f}^{0}$ toward its geostatic limit $\sigma_{n}$ (normal stress acting on the shear band), which corresponds to full fluidization. The corresponding temperature rise is simply obtained by dividing the pore pressure rise $\sigma_{n}-P_{f}^{0}$ by the undrained pressurization coefficient $\Lambda$. For example, if one considers a fault at $7 \mathrm{~km}$ depth with an initial hydrostatic pore pressure at $70 \mathrm{MPa}$, a geostatic stress at $180 \mathrm{MPa}$, an initial temperature at $210^{\circ} \mathrm{C}$ and an undrained pressurization coefficient $\Lambda$ comprised between 0.1 and $1 \mathrm{MPa} /{ }^{\circ} \mathrm{C}$, the temperature rise obtained is between 110 and $1100^{\circ} \mathrm{C}$. This temperature rise must be seen as a lower bound because, as discussed by Rice [2005], the adiabatic and undrained solution appears to be unstable for localization so that the deformation actually localizes in very narrow zones with thickness between few millimeters and few tens of millimeters as observed in mature fault zones. Another idealized situation is met if one assumes that the strain localization zone is infinitely small. This situation corresponds to the model of slip on a plane for which an analytical solution has been proposed by Rice [2006]. The solution of slip on a plane gives an upper bound for the temperature field and the maximum temperature rise is obtained as $\left(1+\sqrt{\frac{\alpha_{h y}}{\alpha_{t h}}}\right)\left(\frac{\sigma_{n}-P_{f}^{0}}{\Lambda}\right)$ where $\alpha_{h y}$ is the hydraulic diffusivity and $\alpha_{t h}$ is the thermal diffusivity of the medium.

[8] These simple analytical solutions show that the temperature rise which occurs during a rapid slip event may easily reach the temperature limit for the onset of mineral decomposition. Dehydration reactions are potentially a major source of fluid and consequently may enhance the generation of pore pressure excess. This production of fluid is in competition with the change of porosity induced by the reduction of solid volume. Obviously the competing effects of temperature rise (due to shear heating), thermal fluid pressurization, mineral decomposition and porosity/permeability increase induce strong nonlinearities in the problem of pore pressure and temperature evolution of a rapidly sheared fault zone. The kinetics of the chemical reaction of mineral decomposition is also a major factor that competes with heat and fluid diffusion processes. The endothermic character of the chemical reaction plays also a role in the energy balance of the system.

[9] Several experimental studies on dehydrating rocks have shown that loss of strength and embrittlement may occur if excess pore pressures are induced. This was first observed by Raleigh and Paterson [1965] and Heard and Rubey [1966] in experiments on serpentinite and gypsum, respectively. For gypsum dehydration, more recent experimental and microstructural investigations of Olgaard et al. [1995] and Ko et al. [1995] have shown that porosity and permeability change appreciably during dehydration reaction. After an initial weakening and embrittlement corresponding to a pulse of excess pore pressure in the sample, subsequent strengthening is caused by a decrease in pore pressure due to porosity increase 


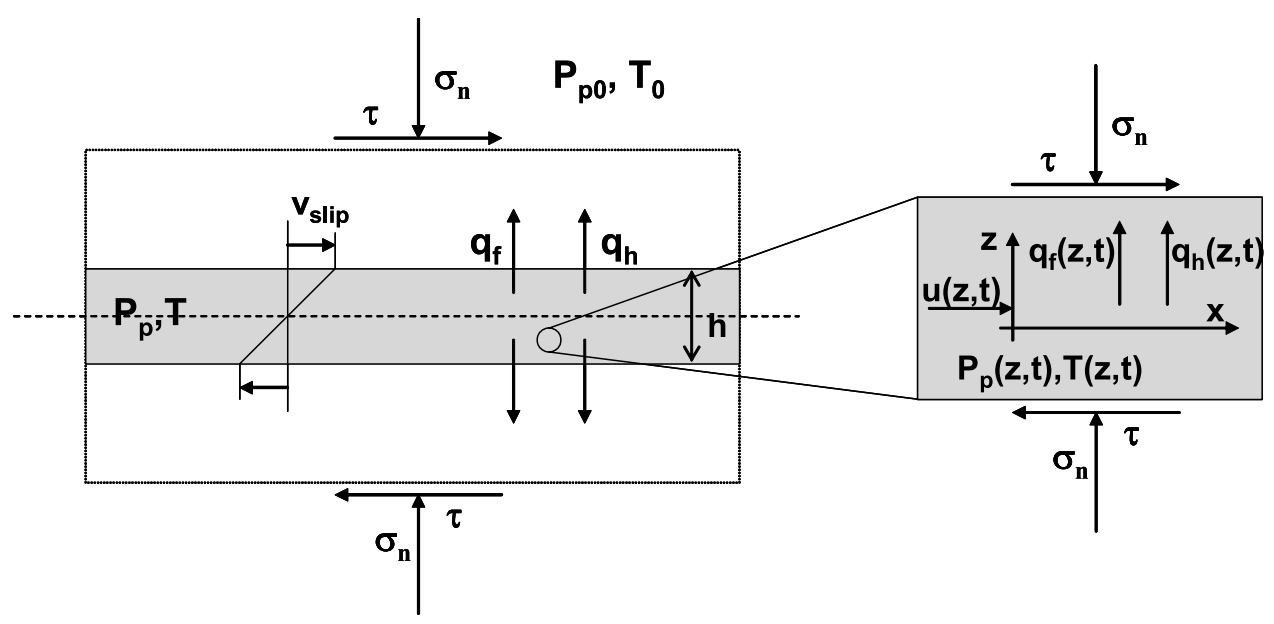

Figure 1. Model of a deforming shear band with heat and fluid fluxes.

and the higher strength of the bassanite produced by the dehydration reaction. Decomposition of kaolinite during high-velocity friction experiments was recently reported and proved to affect pore fluid pressurization during a seismic event [Brantut et al., 2008].

[10] There is evidence of $\mathrm{CO}_{2}$ release in several active crustal faults. In the Corinth rift (Greece) for example, chemical analyzes of water springs near the seismogenic Heliki and Aegion faults revealed an anomalously high content of dissolved $\mathrm{CO}_{2}$ compared with the regional values [Pizzino et al., 2004]. The surface trace of the San Andreas fault also displays a positive anomaly of $\mathrm{CO}_{2}$ fluxes [ Lewicki and Brantley, 2000], and this $\mathrm{CO}_{2}$ comes from a shallow source, not from the mantle [Lewicki et al., 2003]. Moreover, there is growing evidence that $\mathrm{CO}_{2}$ release coincides with seismic slip in crustal faults, active and/or exhumed. Sato and Takahashi [1997] also reported that the $\mathrm{HCO}_{3}^{-}$concentration increased by $30 \mathrm{wt} \%$ in springs located near the Nojima fault (Japan) immediately after the 1995 Kobe earthquake. This carbon discharge, together with other coseismic geochemical anomalies, decreased gradually to normal values in the following ten months. A microinfrared analysis of exhumed pseudotachylites (i.e. friction induced melts produced by seismic slip) from the Nojima fault revealed a carbon supersaturation in the melts, and the quantity of $\mathrm{CO}_{2}$ released by friction melting during the 1995 Kobe earthquake was evaluated to 1.8 to $3.410^{3}$ tons [Famin et al., 2008]. We emphasize that the carbon had a biogenic isotopic signature both in springs and in the fault rocks, and did not correspond to carbon dioxide degassing from the mantle [Ueda et al., 1999; Arai et al., 2001, 2003; Lin et al., 2003]. The $\mathrm{CO}_{2}$ of the Nojima fault might thus be attributed to the decomposition of biogenic carbonates. In the Central Apennines, Italiano et al. [2008] also reported enhanced fluxes of crustal $\mathrm{CO}_{2}$ (i.e. not mantellic) during the 1997-1998 seismic crisis of major faults, and proposed that coseismic decarbonation was responsible for the $\mathrm{CO}_{2}$ emission. Recent studies of the Chelungpu Fault (Taiwan) responsible for the 1999 ChiChi earthquake also showed that the fault core was depleted in carbon relative to the damage zone, and the depletion was attributed to a decarbonation induced by frictional heat [Hirono et al., 2006,
2007]. In addition, recent high-velocity friction experiments on Carrara marble have shown that thermal decomposition of calcite due to frictional heating induces a pronounced fault weakening [Han et al., 2007]. The production of coseismic $\mathrm{CO}_{2}$ is therefore attested by various field and experimental observations, thus making the thermal decomposition of carbonates and the production of $\mathrm{CO}_{2}$ an important additional mechanism to be investigated among possible fault weakening processes.

\section{Description of the Model and Governing Equations}

[11] In this chapter, we introduce the chemical coupling of calcite volume loss and $\mathrm{CO}_{2}$ production in the mechanical analysis of shear heating and fluid pressurization phenomenon.

[12] We consider a rapidly deforming and infinitely long shear band of thickness $h$ consisting of fluid-saturated carbonate rock. This shear band begins to undergo slip $\delta$ at a time $t=0$ with an imposed overall slip rate $V=d \delta / d t$ in the $x$ direction, as shown in Figure 1. For simplicity, it is assumed that the porosity of the fault zone is saturated with pure $\mathrm{CO}_{2}$, even though other fluids such as $\mathrm{H}_{2} \mathrm{O}$ may be dominant before an earthquake. This assumption does not yield significant error in the calculation because the compressibility factors and viscosities of $\mathrm{H}_{2} \mathrm{O}$ and $\mathrm{CO}_{2}$ are nearly equal within the pressure and temperature range considered here. For these conditions of pressure and temperature, carbon dioxide is in supercritical state.

[13] Inside such a shear band the pore pressure $P_{p}(t, z)$, the temperature $T(t, z)$, and the velocity $v(t, z)$ are assumed to be functions only of time $t$ and of the position $z$ in the direction normal to the band (Figure 1).

\subsection{Mass Balance}

[14] Conservation of fluid mass is expressed by

$$
\frac{\partial m_{f}}{\partial t}=\frac{\partial m_{d}}{\partial t}-\frac{\partial q_{f}}{\partial z}
$$

where $m_{f}$ is the total fluid mass per unit volume of porous medium (in the reference state), $m_{d}$ is the mass of emitted 
$\mathrm{CO}_{2}$ per unit volume and $q_{f}$ is the flux of fluid. The total fluid mass per unit volume of porous medium is written as $m_{f}=\rho_{f} n$, where $n$ is the pore volume fraction (Lagrangian porosity) and $\rho_{f}$ is the density of the fluid (here supercritical $\mathrm{CO}_{2}$ ). The left hand side of equation (1) is obtained by differentiating this product,

$$
\frac{\partial m_{f}}{\partial t}=n \frac{\partial \rho_{f}}{\partial t}+\rho_{f} \frac{\partial n}{\partial t}
$$

[15] The derivatives of the right hand side of equation (2) are given by

$$
d \rho_{f}=\rho_{f} \beta_{f} d P_{p}-\rho_{f} \lambda_{f} d T
$$

and

$$
\frac{\partial n}{\partial t}=n \beta_{n} \frac{\partial P_{p}}{\partial t}+\eta \lambda_{n} \frac{\partial T}{\partial t}+\frac{\partial n_{d}}{\partial t}
$$

where $P_{p}$ is pore pressure of the fluid; $\beta_{f}$ and $\lambda_{f}$ are compressibility and thermal expansion coefficient of the pore fluid, respectively. $\beta_{n}$ is the pore volume compressibility and $\lambda_{n}$ is the thermal expansion coefficient of the pore volume, which is equal to the thermal expansion coefficient of the solid fraction for thermoporoelastic materials.

[16] In equation (4), $\frac{\partial n_{d}}{\partial t}$ is the rate of inelastic porosity change. This term includes the effect of coseismic dilatancy $\frac{\partial n_{p}}{\partial t}$, induced by fault surface irregularities and the effect of the decomposition of the solid phase. As shown by Rice [2006], the effect of dilatancy during shear (which is expected to develop at the earliest stages of deformation) can be formally included in the equations by reducing the initial ambient pore pressure $P_{p 0}$ by the suction $\frac{1}{n\left(\beta_{f}+\beta_{n}\right)} \Delta n_{p}$ ( $\Delta n_{p}$ is the total inelastic porosity change due to coseismic dilatancy). In the following and in order to examine the sole effect of mineral decomposition, the rate of inelastic porosity change will be assumed to be only due to the decomposition of the solid phase and expressed as

$$
\frac{\partial n_{d}}{\partial t}=-\frac{1}{\rho_{s}} \frac{\partial m_{s}}{\partial t}
$$

where $P_{p}$ is the density of the solid phase and $m_{s}$ is the mass of the solid phase per unit volume of porous medium.

[17] Using equations (2)-(4), the first term of equation (1) is thus evaluated as [see also Wong et al., 1997; Rice, 2006; Sulem et al., 2007]

$$
\frac{\partial m_{f}}{\partial t}=n \rho_{f}\left(\beta_{n}+\beta_{f}\right) \frac{\partial P_{p}}{\partial t}-\rho_{f} n\left(\lambda_{f}-\lambda_{n}\right) \frac{\partial T}{\partial t}+\rho_{f} \frac{\partial n_{d}}{\partial t}
$$

[18] Following the idea of Hirono et al. [2007], the rate of emitted $\mathrm{CO}_{2}$ is expressed using the kinetics of the chemical reaction of calcite thermal decomposition

$$
\mathrm{CaCO}_{3} \rightarrow \mathrm{CaO}+\mathrm{CO}_{2}
$$

[19] The relationship between the rate of emitted $\mathrm{CO}_{2}$ and the temperature is expressed by the Arrhenius equation,

$$
\frac{\partial m_{d}}{\partial t}=\chi \rho_{s}(1-n) A \exp \left(-\frac{E_{a}}{R T}\right)
$$

where $\chi$ is the ratio between the molar mass $M_{\mathrm{CO} 2}$ of $\mathrm{CO}_{2}$ (44 g/mol) and the molar mass $M_{\mathrm{CaCO} 3}$ of calcite $(100 \mathrm{~g} /$ mol) if we assume that the total amount of calcite can be decomposed; $A$ is a constant (preexponential term of the Arrhenius law); $E_{a}$ is the activation energy of the reaction, $R$ is the gas constant $\left(8.31447 \mathrm{~J} \mathrm{~K}^{-1} \mathrm{~mol}^{-1}\right), T$ is the temperature.

[20] In the following we will take the values corresponding to $\mathrm{CaCO}_{3}$ mixed with silica: $E_{a}=319000 \mathrm{Jmol}^{-1}, A=2.95 \times$ $10^{15} \mathrm{~s}^{-1}$ [Dollimore et al., 1996]. Note that in more complex models of calcite thermal decomposition, A depends on the partial pressure of $\mathrm{CO}_{2}$ [L'vov, 2002, 2007; L'vov and Ugolkov, 2004]. These models, however, have been built for low partial pressures of $\mathrm{CO}_{2}(<0.1 \mathrm{MPa})$ and cannot be applied to our case. We emphasize the need for more realistic kinetic laws of calcite thermal decomposition in the pressure range $10-100 \mathrm{MPa}$.

[21] The relationship between the change of solid mass (per unit volume) and the rate of emitted $\mathrm{CO}_{2}$ is simply given by

$$
\frac{\partial m_{s}}{\partial t}=-\frac{M_{C a C O 3}}{M_{C O 2}} \frac{\partial m_{d}}{\partial t}=-\frac{1}{\chi} \frac{\partial m_{d}}{\partial t}=-\rho_{s}(1-n) A \exp \left(-\frac{E_{a}}{R T}\right)
$$

[22] The flux term in equation (1) is evaluated assuming Darcy's law for fluid flow with viscosity $\eta_{f}$ through a material with permeability $k_{f}$,

$$
q_{f}=-\frac{\rho_{f}}{\eta_{f}} k_{f} \frac{\partial P_{p}}{\partial z}
$$

[23] Substituting, and into gives the fluid mass conservation equation,

$$
\begin{aligned}
\frac{\partial p}{\partial t}= & \Lambda \frac{\partial T}{\partial t}+\frac{1}{n \rho_{f}\left(\beta_{n}+\beta_{f}\right)} \frac{\partial}{\partial z}\left(\rho_{f} \frac{k_{f}}{\eta_{f}} \frac{\partial P_{p}}{\partial z}\right) \\
& +\frac{\chi \rho_{s}-\rho_{f}}{n \rho_{f}\left(\beta_{n}+\beta_{f}\right)}(1-n) A \exp \left(-\frac{E_{a}}{R T}\right),
\end{aligned}
$$

where

$$
\Lambda=\frac{\lambda_{f}-\lambda_{n}}{\beta_{f}+\beta_{n}}
$$

is the thermoelastic pressurization coefficient under undrained conditions [Rice, 2006]. This coefficient is pressure and temperature dependent because the compressibility and the thermal expansion coefficients of the fluid vary with pressure and temperature, and also because the compressibility of the pore space of the rock can change with the effective stress [Ghabezloo and Sulem, 2009].

[24] We observe in equation (11) that, if, $\chi \rho_{s}-\rho_{f}=0$, then the source term coming from thermal decomposition of calcite vanishes. This corresponds to the case for which the overpressure induced by the fluid mass production is exactly compensated by the porosity increase induced by the solid decomposition. With $\chi=0.44$ and $\rho_{s}=2700 \mathrm{~kg} / \mathrm{m}^{3}$, the corresponding fluid density would be $1188 \mathrm{~kg} / \mathrm{m}^{3}$. For $\mathrm{CO}_{2}$, 
such a density corresponds to relatively low temperatures $\left(\sim 100^{\circ} \mathrm{C}\right)$ and high pressures $(\sim 260 \mathrm{MPa})$. However, these thermodynamical conditions are not met in the applications considered in this study.

\subsection{Energy Balance Equation}

[25] The thermal decomposition of calcite is endothermic. Therefore the equation of conservation of energy is expressed as

$$
\rho C \frac{\partial T}{\partial t}+\frac{\partial q_{h}}{\partial z}-\Psi_{p}-\frac{\Delta_{r} H_{T}^{0}}{\chi M_{\mathrm{CaCO}_{3}}}\left(\frac{\partial m_{d}}{\partial t}\right)=0
$$

where $\rho C$ is the specific heat per unit volume of the fault material in its reference state, $q_{h}$ is the heat flux, $\Psi_{p}$ is the rate of mechanical energy dissipation due to inelastic deformation, $\Delta_{r} H_{T}^{0}$ is the enthalpy change of the reaction (i.e. the energy consumed by the reaction), which for calcite decomposition is equal to the activation energy $E_{a}$ in the isobaric mode [L'vov, 2002, 2007; L'vov and Ugolkov, 2004]. Note that in the lack of experimental data, we make here the basic assumption that all the plastic work is converted into heat. We could introduce here the TaylorQuinney coefficient $\beta$ which represents the fraction of plastic work converted into heat. For metals, this coefficient takes values between 0.2 and 0.9 and the remainder contributes to the stored energy of cold work due to the creation of crystal defects. Rosakis et al. [2000] proposed a general internal variable theory in order to explain, within a thermodynamic framework, the validity of such a correction to the heat source term. These authors pointed out that the correction factor $\beta$ is a function of state and can vary in a wide range. In a recent paper, Brantut et al. [2008] have performed high-velocity friction experiments on kaolinite-bearing natural gouge samples and have estimated the amount of energy involved in grain size reduction, in heat production and also in dehydration and amorphization. These authors have shown that most of the energy is either converted into heat or radiated energy. Acoustic measurements could be used for the evaluation of the radiated energy. In the following, we postulate $\beta=1$, however for large earthquakes, the surface energy involved in grain size reduction and microcracking might not be negligible in the energy budget.

[26] The heat flux is related to the temperature gradient by Fourier's law,

$$
q_{h}=-k_{T} \frac{\partial T}{\partial z}
$$

where $k_{T}$ is the thermal conductivity of the saturated material. In equation (13) it is assumed that all heat flux is due to heat conduction neglecting heat convection by the moving hot fluid. This assumption is justified by the low pore volume fraction and the low permeability of fault gouges [Lee and Delaney, 1987]. As shown by these authors, for permeability less than $10^{-16} \mathrm{~m}^{2}$ as typical for crystalline rocks, the advective term is negligibly small. However, this assumption should be relaxed in case of a seismically induced high permeability in the wall rocks of the fault. Inelastic porosity increase with increasing slip will induce an increase of the permeability and consequently a reduction of pore pressure in the shear heating zone and also a cooling of the slipping zone because of the expulsion of the hot fluids.

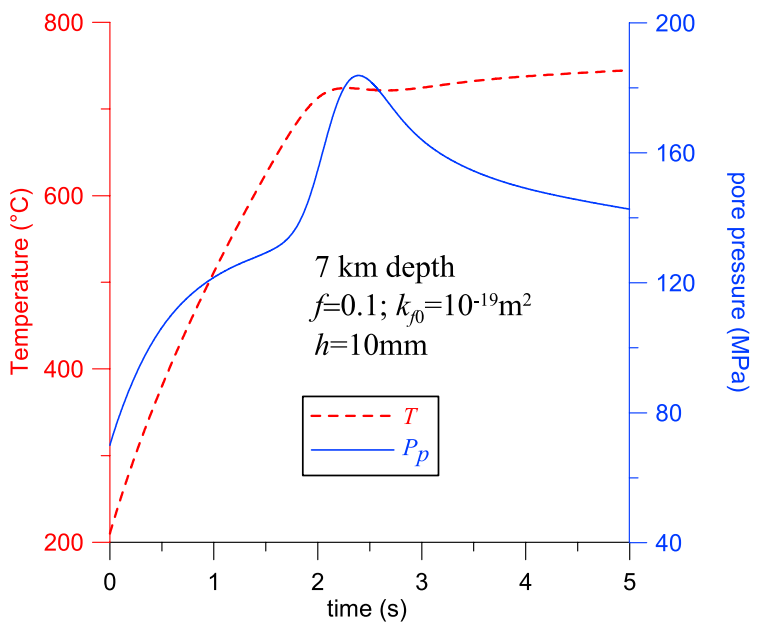

(a)

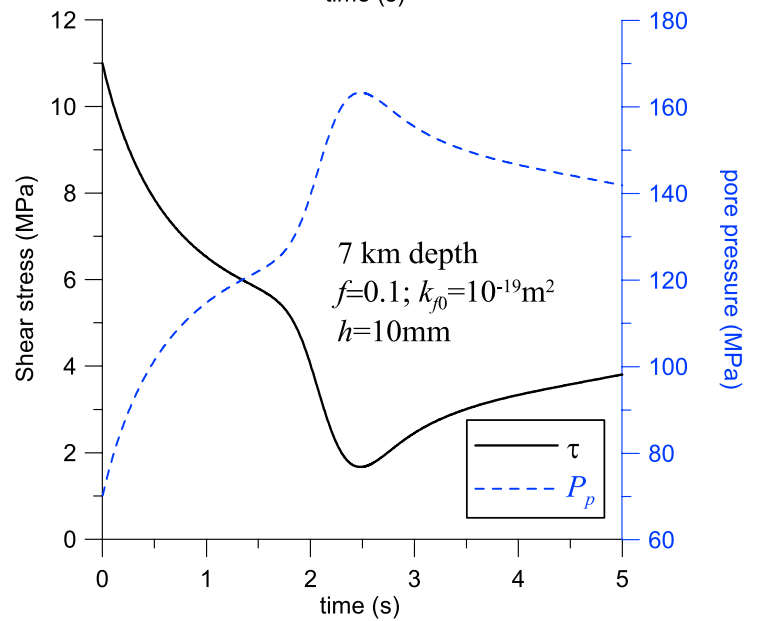

(b)

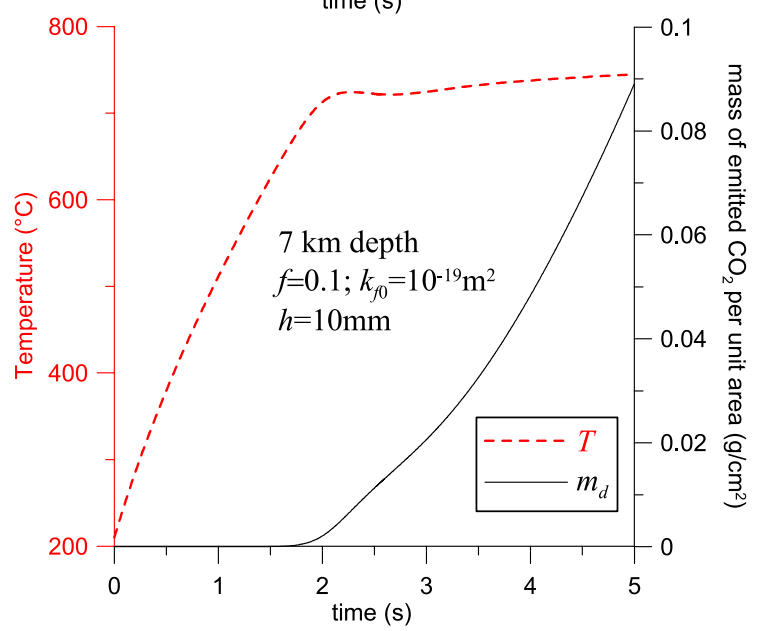

(c)

Figure 2. Fault at 7-km depth. (a) Evolution of temperature and pore pressure in the center of the shear band, (b) evolution of the shear stress, and (c) evolution of the mass of emitted $\mathrm{CO}_{2}$.

[27] If we neglect all dissipation in the fluid the rate of mechanical energy dissipation is written as

$$
\Psi_{p}=\tau \frac{\partial v}{\partial z}
$$




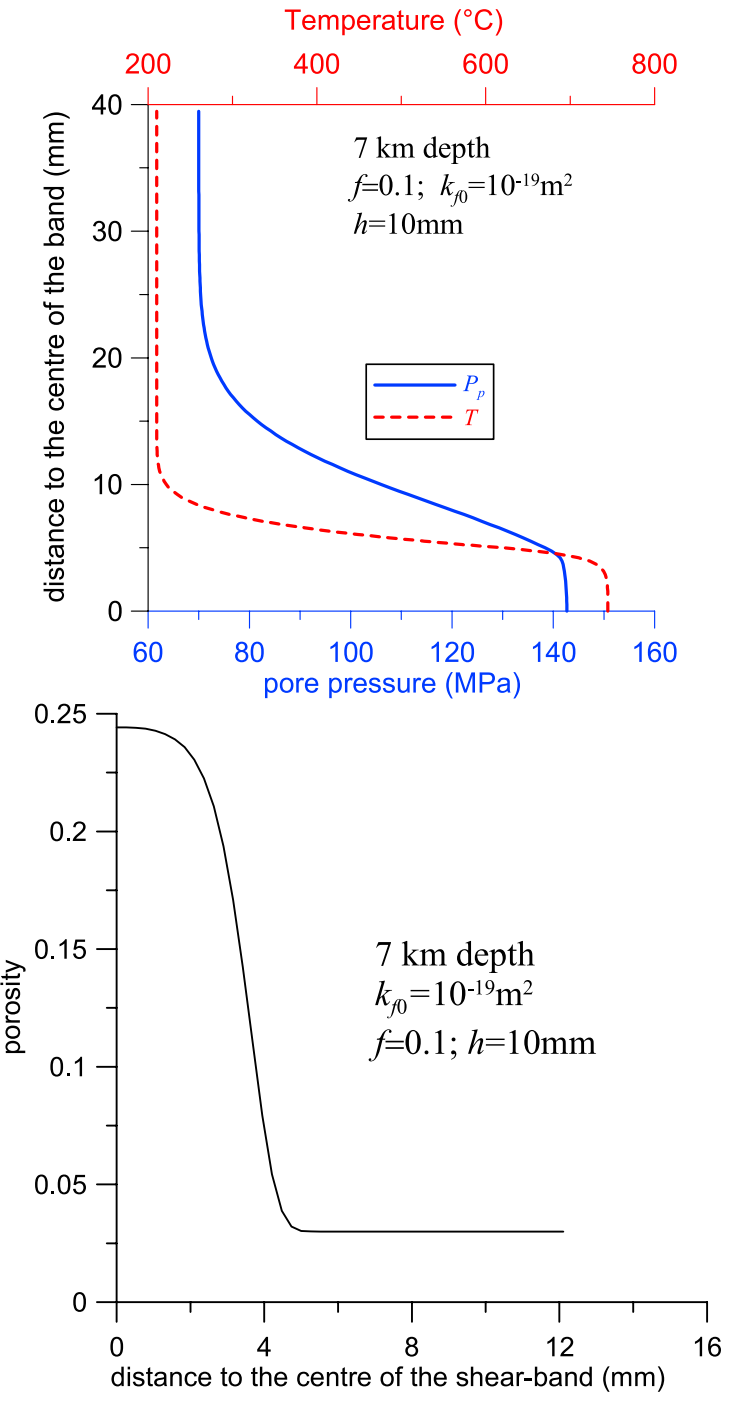

Figure 3. Fault at 7-km depth: (a) Pore pressure and temperature and (b) porosity fields after $5 \mathrm{~s}$.

where $v$ is the local fault parallel velocity and $\tau$ is the shear stress. In equation (15) the work done by the normal stress $\sigma_{\mathrm{n}}$ is considered negligible as compared to the one done by $\tau$ at the large shear considered.

[28] Substituting (14) and (15) into (13) gives the energy conservation equation,

$\frac{\partial T}{\partial t}=\frac{1}{\rho C} \frac{\partial}{\partial z}\left(k_{T}\left(\frac{\partial T}{\partial z}\right)\right)+\frac{1}{\rho C} \tau \frac{\partial v}{\partial z}-\frac{1}{\rho C} \frac{\Delta_{r} H_{T}^{0}}{\chi M_{\mathrm{CaCO}_{3}}}\left(\frac{\partial m_{d}}{\partial t}\right)=0$

\subsection{Momentum Balance Equation}

[29] The momentum balance equation is restricted in this study to the one-dimensional formulation in the $z$ direction as the length scales in the direction parallel to the fault over which the mechanical fields vary are much larger than in the direction normal to it. The one-dimensional momentum balance equation reads as

$$
\frac{\partial \tau}{\partial z}=\rho \frac{\partial v}{\partial t}
$$

[30] As discussed by Rice [2006], the effect of even large accelerations like several times the acceleration of the gravity $g$ is insignificant over the small length scales in the $z$ direction normal to the fault where the heat and fluid diffusion processes are taking place during rapid slip and at very high values of pressure and temperature gradients. For example, assuming an acceleration of $10 \mathrm{~g}$ and a specific mass of the material of $2500 \mathrm{~kg} / \mathrm{m}^{3}$ would result in a change of $2.5 \times 10^{-2} \mathrm{MPa} / \mathrm{m}$ for $\tau$. The relevant length scale in $z$ direction is only few centimeters and thus the variation for $\tau$ can be neglected and mechanical equilibrium can be assumed,

$$
\frac{\partial \tau}{\partial z}=0
$$

[31] Consequently, as the shear stress is constant in space, the Coulomb friction law cannot be assumed to be met in all deforming regions unless the pore pressure is also constant in space as it is the case in the undrained adiabatic limit.

[32] It is thus assumed that the frictional resistance is proportional to the mean effective stress inside the band,

$$
\tau(t)=f\left(\sigma_{n}-\frac{1}{h} \int_{-h / 2}^{h / 2} P_{p}(\xi, t) d \xi\right)
$$

where $f$ is the friction coefficient of the fault material and $h$ is the width of the shear band.

\subsection{Summary of the Governing Equations}

[33] The above coupled production/diffusion equations can be summarized as

$$
\begin{aligned}
\frac{\partial p}{\partial t}= & \Lambda \frac{\partial T}{\partial t}+\frac{1}{n\left(\beta_{n}+\beta_{f}\right)} \frac{\partial}{\partial z}\left(\frac{k_{f}}{\eta_{f}} \frac{\partial P_{p}}{\partial z}\right) \\
& +\frac{\chi \rho-\rho_{f}}{n \rho_{f}\left(\beta_{n}+\beta_{f}\right)}(1-n) A \exp \left(-\frac{E_{a}}{R T}\right) \\
\frac{\partial T}{\partial t}= & \frac{1}{\rho C} \frac{\partial}{\partial z}\left(k_{T} \frac{\partial T}{\partial z}\right)+\frac{1}{\rho C} f\left(\sigma_{n}-\frac{1}{h} \int_{0}^{h} P_{p}(\xi, t) d \xi\right) \frac{\partial v}{\partial z}-\frac{(1-n)}{\rho C} \\
& \cdot \frac{\Delta_{r} H_{T}^{0}}{M_{C a C o_{3}}} \rho_{s} A \exp \left(-\frac{E_{a}}{R T}\right)
\end{aligned}
$$

\subsection{Permeability Law}

[34] The decomposition of carbonate can induce substantial change in the porosity of the rock which affects the permeability. It is known that there is no unique relationship between porosity and permeability applicable to all porous media and that the geological evolution process of the pore space influence the permeability-porosity relationship [Bernabé et al., 2003]. The empirical power law $k_{f} \propto n^{\alpha}$ is commonly used for geomaterials. The exponent $\alpha$ characterizes the porosity sensitivity of permeability and can take values ranging from 1 to 25 up to 25 [David et al., 1994]. The high values of $\alpha$ correspond in general to rocks with a high porosity whereas for low porosity rocks law values of $\alpha$ are obtained. The commonly used cubic Carman Kozeny permeability law is assumed here to take into account the 
effect of porosity change due to mineral decomposition on the permeability of the rock,

$$
k_{f}=k_{f 0}\left(\frac{1-n_{0}}{1-n}\right)^{2}\left(\frac{n}{n_{0}}\right)^{3}
$$

where $k_{f 0}$ is the reference permeability corresponding to the reference porosity $n_{0}$. We would like to emphasize the fact that the assumed permeability law has a strong effect on the numerical results and that there is a need for experimental data on permeability changes resulting from the particular process of carbonate decomposition. Moreover, as this particular process during a large shear, it will also result in some specific microtexture, which will probably affect it. In addition, the stress concentration achieved at the rupture tip during crack propagation might induce the formation and opening of secondary cracks that could significantly increase the permeability in the wall rocks [Di Toro et al., 2005]. Once again, in absence of a better knowledge of permeability evolution during seismic slip, a large range of permeabilities has to be explored when considering the effect of thermal pressurization and $\mathrm{CO}_{2}$ production.

\subsection{Thermodynamical Properties of Supercritical $\mathrm{CO}_{2}$}

[35] The above governing equations (20) involve the thermodynamical properties of the pore fluid. The viscosity, the density, the compressibility and the thermal expansion of $\mathrm{CO}_{2}$ in supercritical state have been fitted using the data published by the National Institute of Standards and Technology (http://webbook.nist.gov/chemistry/) and from the state equation proposed by Saxena and Fei [1987] for very high pressures and temperatures. Fitted curves are detailed in Appendix A.

\section{Numerical Examples}

[36] In the following, the system of equation (20) is solved numerically using an explicit 2nd order Runge-Kutta finite difference scheme. The time step used in the RungeKutta method for time integration is. The grid size for space discretization is $h / 20$ ( $h$ being the shear band thickness) and the far field boundary conditions are written at $z=10 \mathrm{~h}$. Among the parameters which appear in the considered problem, some have a major influence on the evolution of the system: the initial sate of stress and initial temperature, the thickness of the sheared zone, the initial permeability of the medium, the friction coefficient.

[37] As pointed out by Rice [2006] and recent field observations suggest that slip in individual events may then be extremely localized, and may occur primarily within a thin shear zone of few millimeters thick [Heermance et al., 2003; Chester et al., 2004; Wibberley and Shimamoto, 2005]. Recent high-velocity friction experiments on natural clayey gouge have also shown that shear occurs in a very localized thin zone of few hundreds of microns [Boutareaud et al., 2008] thick. Note that coseismic dilatancy of the slipping zone thickness, induced by fault surface irregularities, might influence the pressurization of the fluids. As discussed by Vardoulakis [2002], Rempel and Rice [2006], and Sulem et al. [2007] the actual thickness of the "ultra- localized" zone of highly strained material is a key parameter in the analysis.

[38] In the following, we present a reference computation corresponding to some typical values of the parameters, and then the influence of some parameters is discussed and illustrated.

\subsection{Reference Computation}

[39] The reference computation is performed for a fault at $7 \mathrm{~km}$ depth in a carbonate rock. The initial temperature, initial pore pressure and total normal stress are assumed to be $T_{0}=$ $210^{\circ} \mathrm{C}, P_{p 0}=70 \mathrm{MPa}, \sigma_{n}=180 \mathrm{MPa}$. The thermal expansion coefficient of the pore volume is $\lambda_{n}=2.4 \times 10^{-5}\left({ }^{\circ} \mathrm{C}\right)^{-1}$. For the pore volume compressibility, we account for the effect of porosity change due to mineral decomposition and also for the effect of effective stress change due to pore pressure rise. The expression of the pore volume compressibility is obtained from poroelasticity theory and is given by [Rice, 2006; Ghabezloo and Sulem, 2009]

$$
\beta_{n}=\frac{1}{n}\left(\beta_{d}-(1+n) \beta_{s}\right)
$$

where $\beta_{s}$ is the compressibility of the solid phase $(1.25 \times$ $10^{-5} \mathrm{MPa}^{-1}$ for calcite) and $\beta_{d}$ is the drained compressibility of the porous rock. We consider here the empirical expression for the effective stress dependent drained compressibility as proposed by Wibberley and Shimamoto [2005] for the Median Tectonic line fault zone in Japan:

$$
\begin{aligned}
\beta_{d}\left(\text { in }_{\left.\mathrm{MPa}^{-1}\right)=}\right. & 2.5 \times 10^{-4} \exp \left(-1.38 \times 10^{-2}\left(\sigma_{n}-P_{p}\right)\right) \\
& \left(\left(\sigma_{n}-P_{p}\right) \text { in MPa }\right)
\end{aligned}
$$

[40] The initial porosity of the rock is taken equal to 0.03 . The density of the porous rock is taken equal to $\rho=2.6 \mathrm{~g} / \mathrm{cm}^{3}$, the density of the solid phase (calcite) is $\rho_{s}=2.7 \mathrm{~g} / \mathrm{cm}^{3}$, and the specific heat is $\rho C=2.7 \mathrm{MPa} /\left({ }^{\circ} \mathrm{C}\right)$. The recent highvelocity shear experiments on Carrara marble of Han et al. [2007] have shown that the friction coefficient decreases rapidly to values as low as 0.06 due to the thermal decomposition of calcite induced by frictional heating. Here we take $f=0.1$.

[41] We assume that the initial permeability of the intact medium is $k_{f 0}=10^{-19} \mathrm{~m}^{2}$. We consider a shear band with a thickness $\mathrm{h}=10 \mathrm{~mm}$ and we assume that the slip velocity is $V=1 \mathrm{~m} / \mathrm{s}$.

[42] The computed results are presented in Figure 2. The evolution in time of the temperature and the pore pressure in the center of the band is plotted in Figure 2a. Considering a constant slip velocity of $1 \mathrm{~m} / \mathrm{s}$, this graph can also be seen as the evolution of temperature and pore pressure with accumulated slip. The corresponding shear stress is plotted in Figure 2b. These results show the coupling effect of heat which induces first a pore pressure increase. When the decomposition of the carbonate rock begins at about $700^{\circ} \mathrm{C}$, the temperature increase is drastically slowed due to the energy consumed in the endothermic chemical reaction. Two competing effects act on the evolution of the pore pressure: on one hand the production of $\mathrm{CO}_{2}$ induces an additional fluid mass and thus a pressurization 


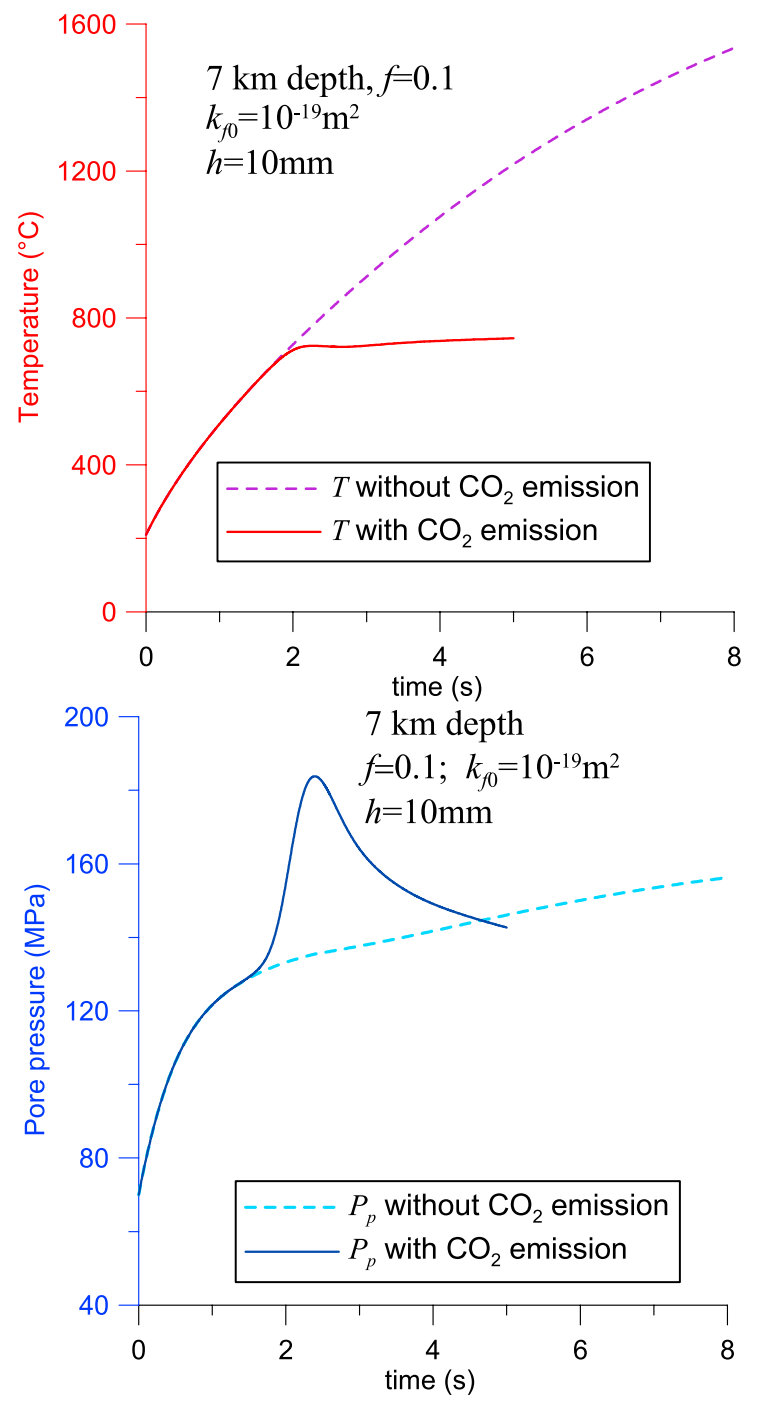

Figure 4. Fault at 7-km depth. Effect of $\mathrm{CO}_{2}$ emission on the evolution of (a) temperature and (b) pore pressure in the center of the shear band.

of the pore fluid, on the other hand the increase of porosity due to the solid decomposition induces an increase of the permeability of the medium which limits the pressurization. The pore pressure in the center of the band exhibits a maximum of about $191 \mathrm{MPa}$ which exceeds the total normal stress acting (180 MPa) on the band which means that the material is locally in the tensile regime. As mentioned above, through the friction law the shear stress is related to the mean effective stress inside the band (Figure 2b). Consequently, the shear stress decreases rapidly during initial pressurization and then increases again. Thus the mineral decomposition of the rock can be seen as a mechanism of fault weakening in a first stage then fault restrengthening in a second stage. The accumulated mass per unit area of the fault plane of emitted $\mathrm{CO}_{2}$ is plotted on Figure 2c. After a few seconds, the temperature reaches a quasi constant state and the production rate is almost constant. These results show that the mass of emitted $\mathrm{CO}_{2}$ after $5 \mathrm{~s}$ is about $0.09 \mathrm{~g} / \mathrm{cm}^{2}$. This corresponds to an amount of $900 \mathrm{t} / \mathrm{km}^{2}$. The pore pressure and temperature field around the center of the band is shown in Figure 3a for $t=$ $5 \mathrm{~s}$ and the porosity is plotted in Figure $3 \mathrm{~b}$. The computation is stopped when the porosity reaches $25 \%$ inside the band corresponding to a permeability of $10^{-16} \mathrm{~m}^{2}$ as the simple cubic Carman-Kozeny permeability law of would be meaningless over larger ranges of porosity variation. As mentioned above (see section 3.2), for a medium with permeability smaller than $10^{-16} \mathrm{~m}^{2}$, neglecting the advective terms in the governing heat and fluid flux equations is an acceptable assumption. Note that the computations are performed here, assuming a constant exponent equal to 3 in the power law relationship between the porosity and the permeability (equation (21)). As shown by David et al. [1994], this exponent is generally higher for high porosity rocks. The plots in Figure 3 show that the pore pressure and temperature increases are localized in the central zone of the band. The porosity is affected only in zones where the temperature
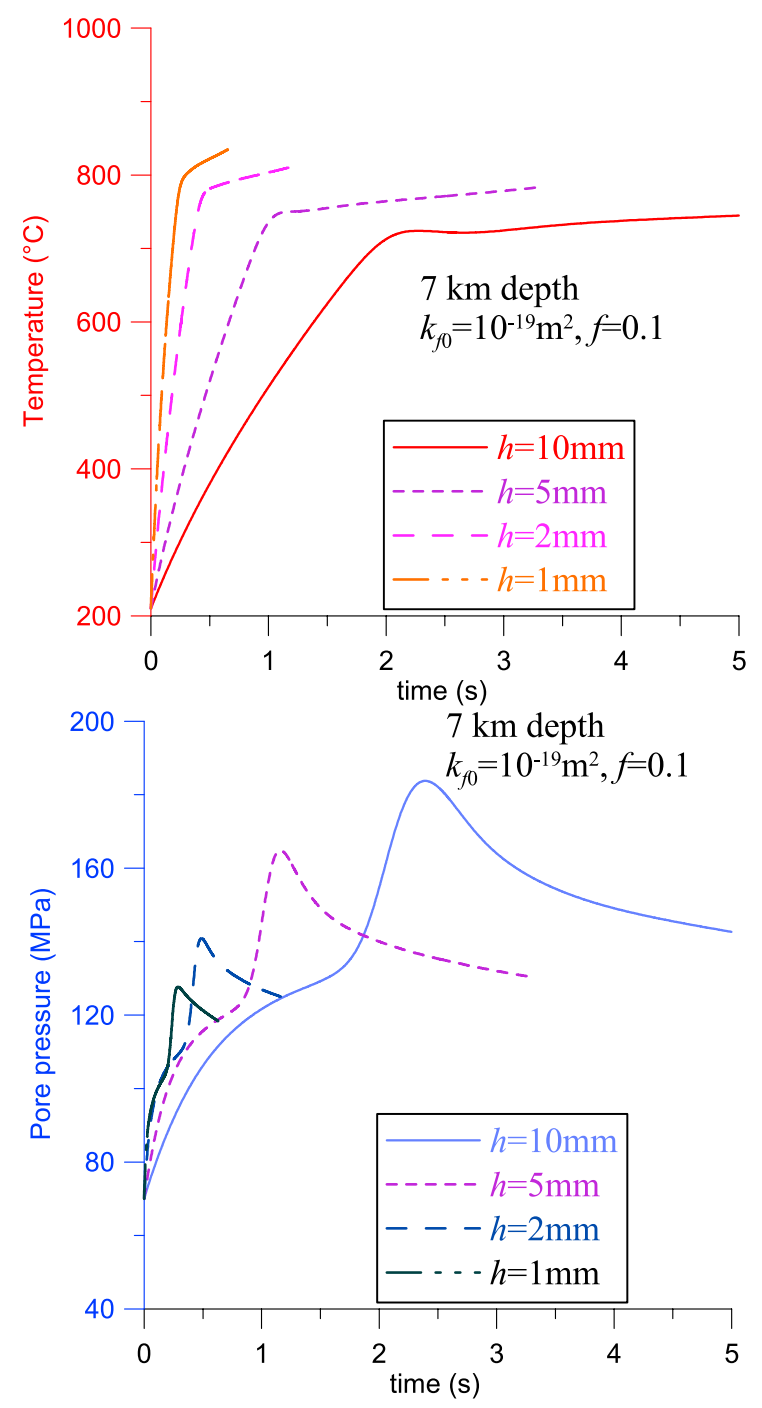

(b)

Figure 5. Fault at 7-km depth. Effect of the shear band thickness. Evolution of (a) temperature and (b) pore pressure in the center of the shear band. 


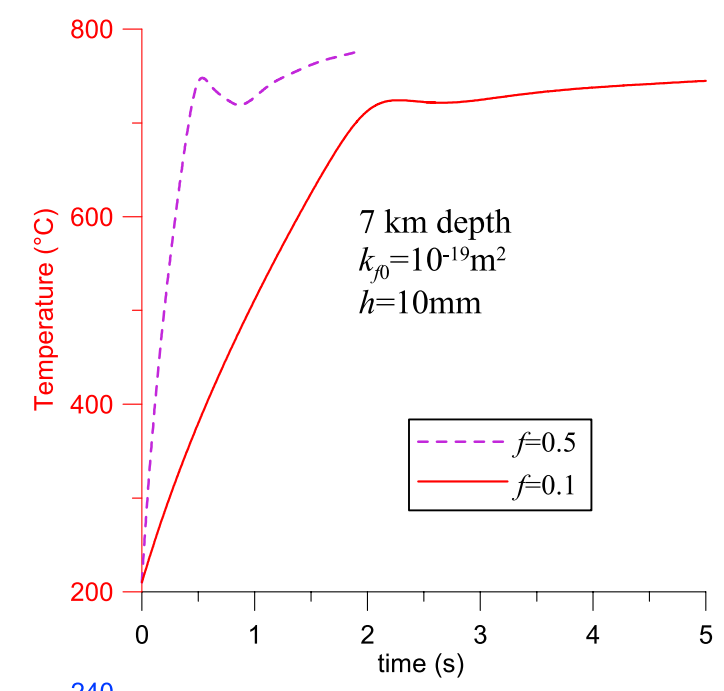

(a)

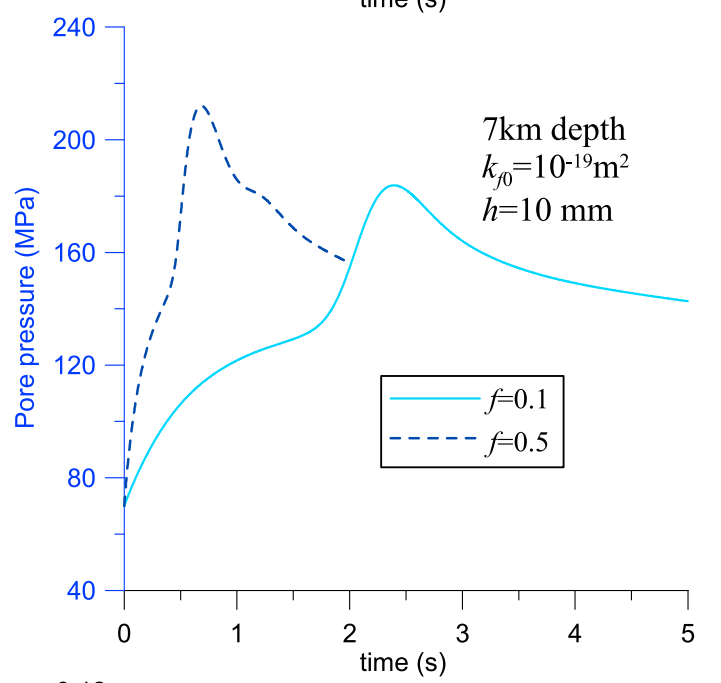

(b)

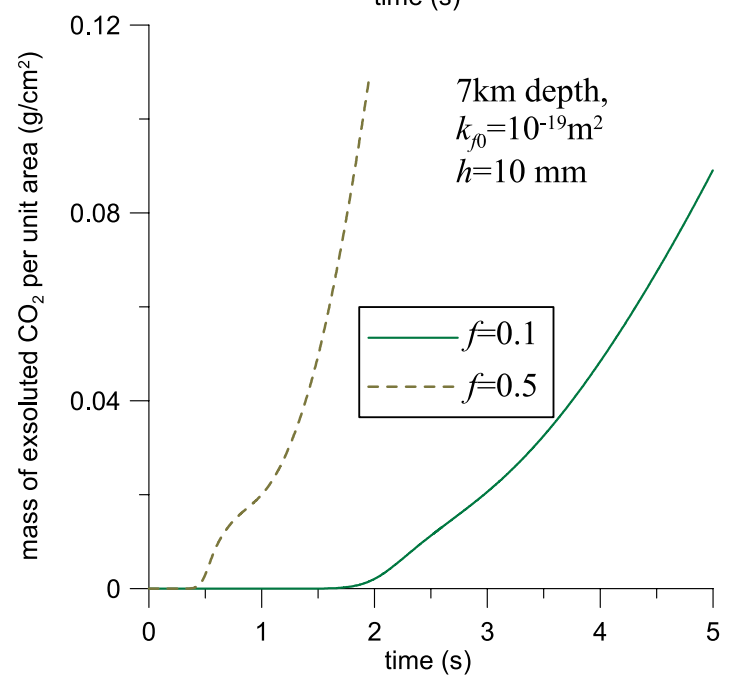

(c)

compared to the ones obtained without $\mathrm{CO}_{2}$ degassing. In this latter case only thermal pressurization occurs. If no mineral decomposition occurs, the pore pressure increase is slower and for the considered parameters, full liquefaction

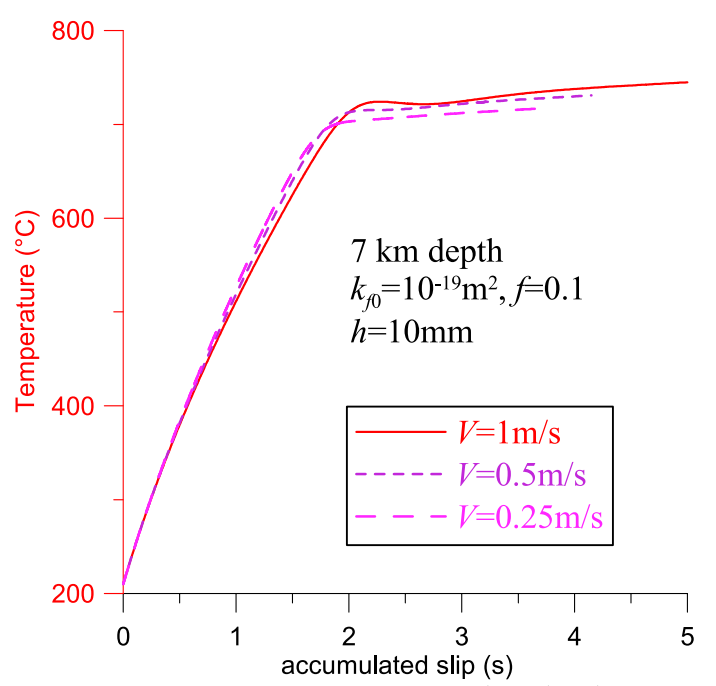

(a)

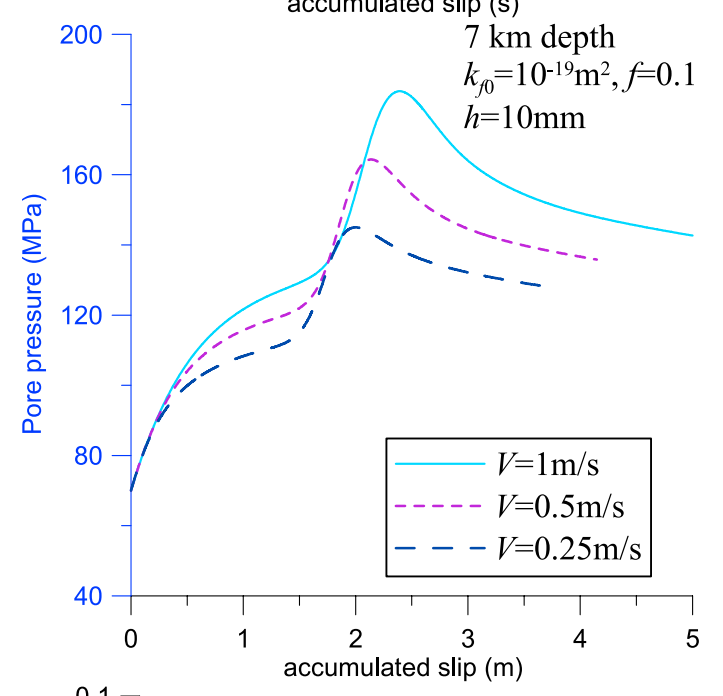

(b)

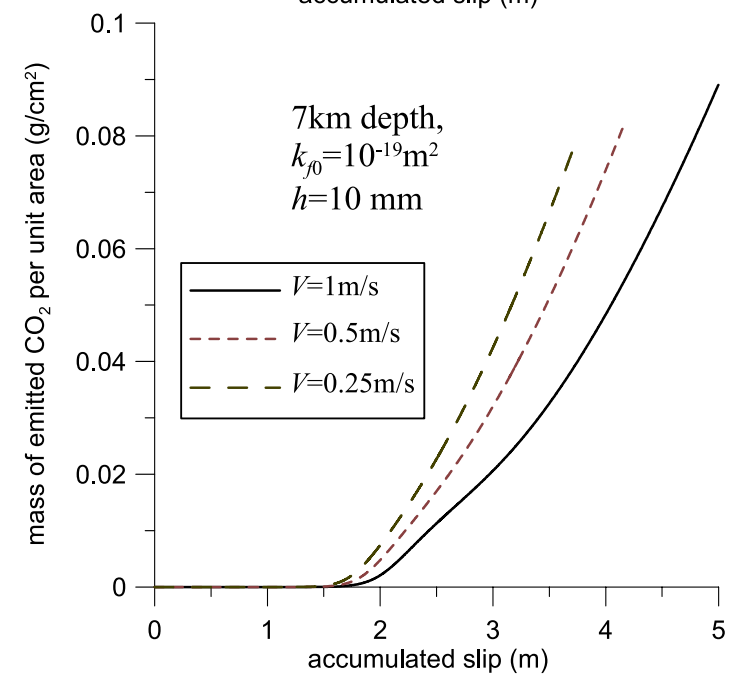

(c)

Figure 6. Fault at 7-km depth. Effect of the friction coefficient. Evolution of (a) temperature, (b) pore pressure, and (c) mass of emitted $\mathrm{CO}_{2}$ in the center of the shear band.

exceeds $700^{\circ} \mathrm{C}$ which for the considered computation corresponds to a width of about $8 \mathrm{~mm}$.

[43] The effect of mineral decomposition is also shown in Figure 4 where the results of the above computation are

Figure 7. Fault at 7-km depth. Effect of the slip velocity. Evolution of (a) temperature, (b) pore pressure, and (c) mass of emitted $\mathrm{CO}_{2}$ in the center of the shear band. 

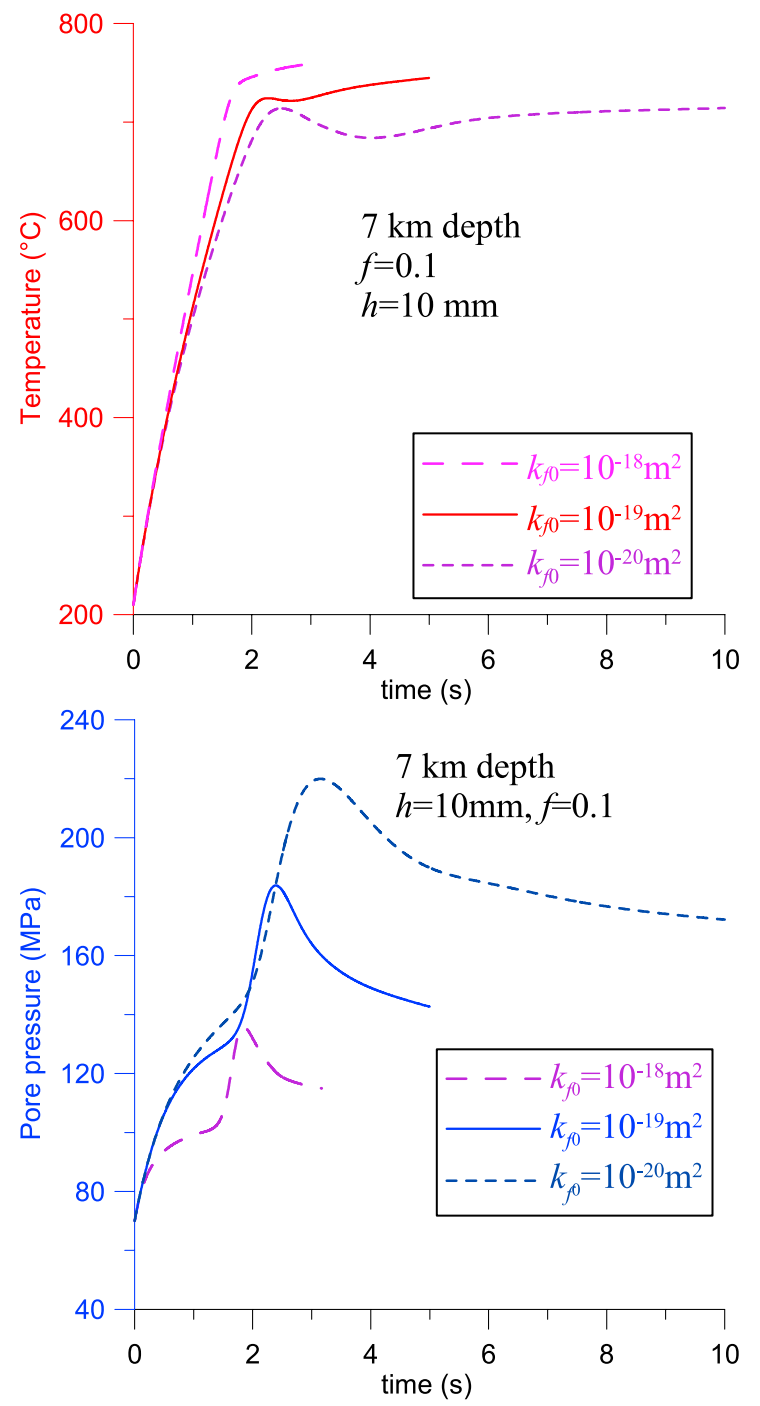

Figure 8. Fault at 7-km depth. Effect of the initial permeability. Evolution of (a) temperature and (b) pore pressure in the center of the shear band.

is not attained and consequently the temperature increase is much stronger and melting of the rock can occur (the melting temperature is about $1600^{\circ} \mathrm{C}$ for calcite).

\subsection{Influence of Some Parameters}

\subsubsection{Effect of the Shear Band Thickness}

[44] The effect of the shear band thickness is shown in Figure 5 where the results of computations performed with $h=1,2,5,10 \mathrm{~mm}$ respectively are compared. These computations are done keeping all the other parameters unchanged.

[45] The widths used in the computation correspond to the range of shear band thicknesses found in natural faults [Wibberley and Shimamoto, 2005; Rice, 2006]. The $10 \mathrm{~mm}$ thickness, a rather large value of slipping zone width, is considered to take into account some possible asperity induced dilation during slip. Our model predicts that a thinner shear band yields a quicker and sharper pore pressure pulse during slip, and a stronger temperature increase.

\subsubsection{Effect of the Friction Coefficient}

[46] The results of two computations corresponding respectively to $f=0.1$ and $f=0.5$ are compared in Figure 6 . The pore pressure pulse is more pronounced for a higher friction coefficient. The temperature increase is faster but the maximum temperature is not much affected. The corresponding mass of emitted $\mathrm{CO}_{2}$ is also increasing faster.

\subsubsection{Effect of the Slip Velocity}

[47] The effect of the slip velocity is shown in Figure 7 where the computed results obtained with velocities of 0.25 , 0.5 and $1 \mathrm{~m} / \mathrm{s}$ are compared. Note that on these graphs, the pore pressure and the temperature in the center of the shear band as well as the mass of emitted $\mathrm{CO}_{2}$ are plotted versus the accumulated slip. It is obtained that for a slower slip rate the pore pressure pulse and the temperature increase are delayed but the evolution of the temperature is not affected by the slip velocity and is only controlled by the accumulated slip. This is due to the very small thermal diffusivity of the material. The pore pressure increase is less important for a lower value of the slip rate which reflects the effect of fluid diffusion outside of the sheared zone.

4.2.4. Effect of the Initial Permeability

[48] The effect of initial permeability is shown in Figure 8. Its effect is comparable to the effect of the thickness of the shear band: a higher initial permeability (resp. a thinner shear band) leads to a shorter pore pressure pulse and a higher temperature.

\subsubsection{Effect of the Initial State of Stress and Initial Temperature}

[49] The same computations have been performed for the conditions of a fault at $5 \mathrm{~km}$ depth. In this case it is assumed that initial temperature, initial pore pressure and total normal stress are respectively $T_{0}=150^{\circ} \mathrm{C}, P_{p 0}=50 \mathrm{MPa}$, $\sigma_{n}=130 \mathrm{MPa}$. It is also assumed that the friction coefficient is $f=0.1$. The numerical results are shown in Figure 9. As expected the pore pressure pulse is less pronounced and the temperature increase is slower at lower depth.

[50] It is worth noticing that for all these computations, the temperature reaches a quasi constant value between $700^{\circ} \mathrm{C}$ and $800^{\circ} \mathrm{C}$ which corresponds to the initiation of the carbonate decomposition and that the temperature increase is limited due the endothermic character of the chemical reaction.

\section{Concluding Discussion}

[51] A first essential result of our model is that the endothermic reaction of calcite decomposition limits the coseismic temperature increase to less than $\sim 800^{\circ} \mathrm{C}$ (corresponding to the initiation of the chemical reaction) within a carbonate shear band under rapid slip. Depending on the slip velocity, the temperature limitation induced by decarbonation begins 1 to $4 \mathrm{~s}$ after the rupture (Figure 7). According to empirical relationships [Kanamori and Brodsky, 2004], slip durations longer than $1 \mathrm{~s}$ occur for mostly earthquakes with $\mathrm{Mw} \geq 5$. This leads to the counterintuitive conclusion that large earthquakes are more prone to develop temperature limitation by endothermic reactions than smaller ones. Decarbonation is only one of the possible thermal reactions of mineral decomposition. Phyllosilicates are common secondary minerals in faults and their reaction of thermal dehydration is 

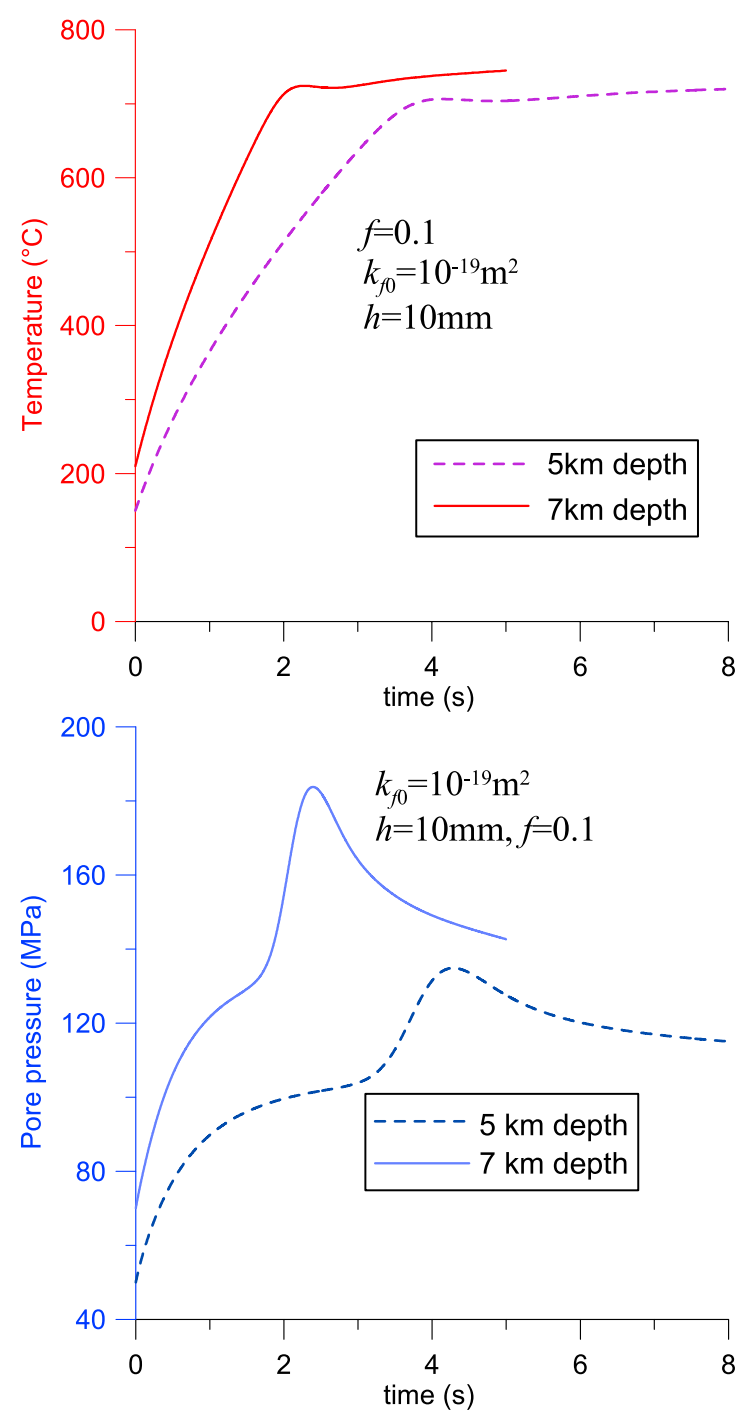

Figure 9. Effect of the initial conditions. Evolution of (a) temperature and (b) pore pressure in the center of the shear band.

also endothermic. Therefore it is likely that the reactioninduced temperature limitation obtained in our model may apply qualitatively to most fault zones. In this case, mature faults with a long history of slip and a large cumulated displacement are likely more prone to reaction-induced temperature limitation than recent faults, because of their larger content in volatile-rich secondary minerals. This would provide another explanation to the notorious absence of positive heat flow anomaly on active crustal faults such as San Andreas [Lachenbruch and Sass, 1980]: a large part of the heat produced by friction would be consumed by endothermic reactions. Another consequence of our model is that friction melting is hampered by endothermic calcite decomposition in carbonate fault rocks, and probably in other faults containing a sufficiently high proportion of volatile-rich secondary minerals. This is consistent with the relative scarcity of pseudotachylytes in mature faults such as the Punchbawl fault [Sibson, 1975; Chester et al., 2004; Sibson and Toy, 2006; Di Toro et al., 2006], and their occurrence in less evolved faults such as Nojima [Fujimoto et al., 1999; Ohtani et al., 2000; Tanaka et al., 2001; Otsuki et al., 2003].

[52] The second essential implication of our model is that decarbonation is a source of $\mathrm{CO}_{2}$ that significantly increases the slip-weakening effect of thermal pressurization. The pore fluid pressure exhibits an initial phase of increase due to thermal pressurization, then a sudden acceleration of generated pore pressure when the solid decomposition is activated. However, the increase of permeability limits the pore pressure that reaches a maximum and then decreases. The numerical results reproduce this pore pressure pulse and the initial fault weakening followed by a restrengthening of the shear stress. Our model may be particularly adapted to account for seismic slip in seismogenic normal faults of the Corinth rift (Greece) cutting across mesozoic carbonates at 4-6 km depth [Flotté et al., 2005]. In particular, the active faults of the Gulf of Corinth have produced several earthquakes with $\mathrm{Mw} \geq 5$ in the past decades. The positive $\mathrm{CO}_{2}$ anomaly in springs nearby these faults [Pizzino et al., 2004] might come from slipinduced decarbonation.

[53] Thermal decomposition of rocks appears to be an important physical process in the phenomenon of thermal heating and pore fluid pressurization during seismic slip. The combined effects of frictional heating, temperature rise, endothermic mineral decomposition, pore pressure rise, porosity and permeability increase result in highly coupled and competing processes. Our model of thermal pressurization, taking into account these coupled processes, provides a more robust framework for estimating the dynamic friction of faults and the energy balance of earthquakes.

\section{Appendix A: Thermodynamical Properties of Supercritical $\mathrm{CO}_{2}$}

[54] In this appendix we detail the fitted curves for the viscosity, the density, the compressibility and the thermal expansion of $\mathrm{CO}_{2}$ in supercritical state. These curves have been fitted using the data published by the National Institute of Standards and Technology (http://webbook.nist.gov/ chemistry/) and from the state equation proposed by Saxena and Fei [1987] for very high pressures and temperatures.

\section{A1. Viscosity}

[55] The viscosity $\eta_{f}$ of supercritical $\mathrm{CO}_{2}$ is expressed as a function of the pressure $p$ and the temperature $T$ as follows (Figure A1):

$$
\begin{gathered}
\text { For } 40 \mathrm{MPa} \leq p \leq 200 \mathrm{MPa} \text { and } 200^{\circ} \mathrm{C} \leq T \leq 800^{\circ} \mathrm{C} \\
\left(T \text { in }\left({ }^{\circ} \mathrm{C}\right) \text { and } p \text { in } \mathrm{MPa}, \eta_{f} \text { in } \mu \mathrm{Pa} . \mathrm{s}\right) \\
\begin{aligned}
& a(T)=- 2.3486 \times 10^{-9} T^{3}+4.3520 \times 10^{-6} T^{2} \\
&- 2.9962 \times 10^{-3} T+0.95244 \\
& b(T)= 1.0572 \times 10 \times 10^{-9} T^{4}-2.0919 \times 10^{-6} T^{3}+1.5178 \\
& \times 10^{-3} T-0.44921 T+70.828 \\
& \eta_{f}(T, p)=a(T) p+b(T)
\end{aligned}
\end{gathered}
$$




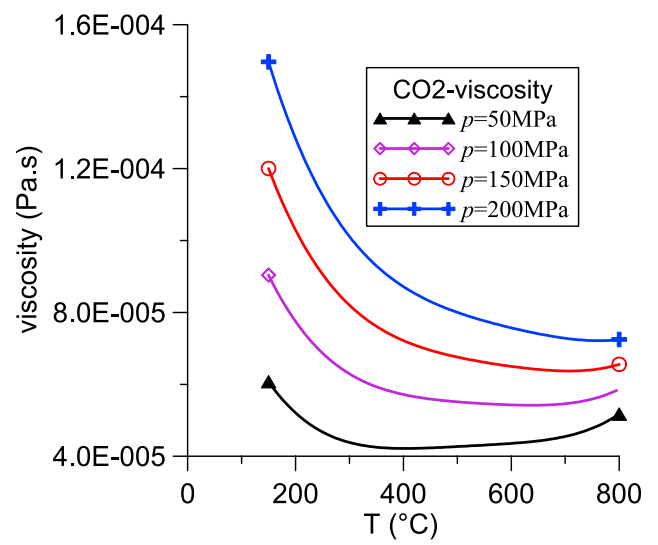

Figure A1. Temperature- and pressure-dependent viscosity of supercritical $\mathrm{CO}_{2}$.

\section{A2. Density}

[56] The density $\rho_{f}$ of supercritical $\mathrm{CO}_{2}$ is expressed as a function of the pressure $p$ and the temperature $T$ as follows:

For $40 \mathrm{MPa} \leq p \leq 200 \mathrm{MPa}$ and $200^{\circ} \mathrm{C} \leq T \leq 800^{\circ} \mathrm{C}$

$$
\begin{aligned}
& \left(T \text { in }\left({ }^{\circ} \mathrm{C}\right) \text { and } p \text { in } \mathrm{MPa}, \rho_{f}=\text { in } \mathrm{g} / \mathrm{l}\right) \\
a(p)= & 6.9255 \times 10^{-18} p^{4}-6.7014 \times 10^{-15} p^{3} \\
& +2.1484 \times 10^{-12} p^{2}-2.8454 \times 10^{-10} p+1.3732 \times 10^{-8} \\
b(p)= & 6.4336 \times 10^{-16} p^{4}-7.0013 \times 10^{-12} p^{3}+3.2851 \times 10^{-9} p^{2} \\
& -5.2198 \times 10^{-7} p+2.8908 \times 10^{-5} \\
c(p)= & -4.1459 \times 10^{-9} p^{3}+2.1070 \times 10^{-6} p^{2}-3.6279 \\
& \times 10^{-4} p+2.3105 \times 10^{-2} \\
d(p)= & -6.6973 \times 10^{-7} p^{3}+4.0528 \times 10^{-4} p^{2}-8.5182 \\
& \times 10^{-2} p+7.9003 \\
h(p)= & 1.2537 \times 10^{-4} p^{3}-4.8800 \times 10^{-2} p^{2}+6.3843 p \\
& +9.6344 \times 10^{2} \\
\rho_{f}(T, p)= & a(p) T^{4}-b(p) T^{3}+c(p) T^{2}-d(p) T+h(p)
\end{aligned}
$$

\section{A3. Compressibility}

[57] The compressibility $\beta_{f}$ of $\mathrm{CO}_{2}$ is expressed as a function of the pressure $p$ and the temperature $T$ as follows (Figure A2):

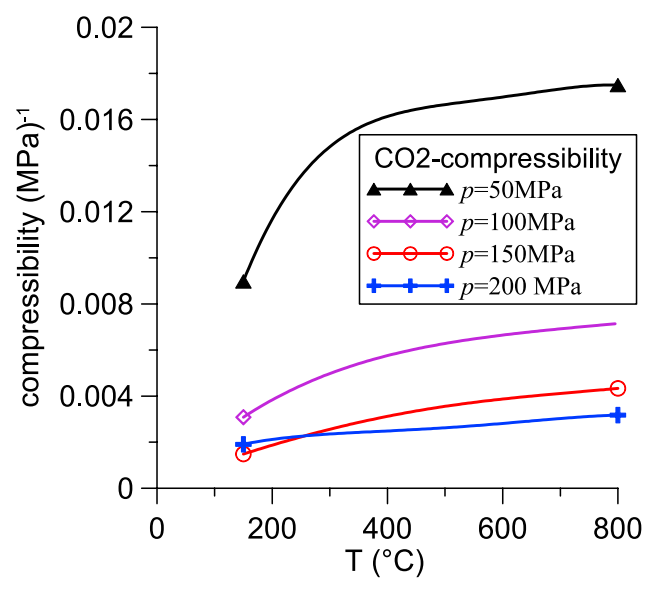

Figure A2. Temperature- and pressure-dependent compressibility of supercritical $\mathrm{CO}_{2}$.
For $40 \mathrm{MPa} \leq p \leq 200 \mathrm{MPa}$ and $200^{\circ} \mathrm{C} \leq T \leq 800^{\circ} \mathrm{C}$

$\left(T\right.$ in $\left({ }^{\circ} \mathrm{C}\right)$ and $p$ in $\mathrm{MPa}, \beta_{f}$ in $\left.\mathrm{MPa}^{-1}\right)$

$$
\begin{aligned}
a_{1}(T)= & -1.6827 \times 10^{-13} T^{4}+4.1050 \times 10^{-10} T^{3}-3.6942 \\
& \times 10^{-7} T^{2}+1.4524 \times 10^{-4} T-1.1643 \times 10^{-2} \\
b_{1}(T)= & -9.6531 \times 10^{-13} T^{4}+2.3536 \times 10^{-9} T^{3}-2.1175 \\
& \times 10^{-6} T^{2}+8.3288 \times 10^{-4} T-6.6064 \times 10^{-2} \\
c_{1}(T)= & -2.1360 \times 10^{-12} T^{4}+5.1711 \times 10^{-9} T^{3}-4.6144 \\
& \times 10^{-6} T^{2}+1.7978 \times 10^{-3} T-1.3717 \times 10^{-1} \\
d_{1}(T)= & -2.1556 \times 10^{-12} T^{4}+5.1688 \times 10^{-9} T^{3}-4.5615 \\
& \times 10^{-6} T^{2}+1.7545 \times 10^{-3} T-1.2436 \times 10^{-1} \\
h_{1}(T)= & -8.2493 \times 10^{-13} T^{4}+1.9708 \times 10^{-9} T^{3}-1.7358 \\
& \times 10^{-6} T^{2}+6.7092 \times 10^{-4} T-4.1694 \times 10^{-2} \\
\beta_{f}(T, p)= & a_{1}(T)(p / 100)^{4}-b_{1}(T)(p / 100)^{3} \\
& +c_{1}(T)(p / 100)^{2}-d_{1}(T)(p / 100)+h_{1}(T)
\end{aligned}
$$

\section{A4. Thermal Expansion}

[58] The thermal expansion $\lambda_{f} \mathrm{CO}_{2}$ is expressed as a function of the pressure $p$ and the temperature $T$ as follows (Figure A3):

For $40 \mathrm{MPa} \leq p \leq 200 \mathrm{MPa}$ and $200^{\circ} \mathrm{C} \leq T \leq 800^{\circ} \mathrm{C}$

$\left(T\right.$ in $\left({ }^{\circ} \mathrm{C}\right)$ and $p$ in $\mathrm{MPa}, \lambda_{f}$ in $\left.\left({ }^{\circ} \mathrm{C}\right)^{-1}\right)$

For $200^{\circ} \mathrm{C} \leq T<600^{\circ} \mathrm{C}$

$a_{2}(p)=9.7187 \times 10^{-17} p^{4}-5.7849 \times 10^{-14} p^{3}+1.2820$

$$
\times 10^{-11} p^{2}-1.2596 \times 10^{-9} p+4.6674 \times 10^{-8}
$$

$b_{2}(p)=1.0018 \times 10^{-13} p^{4}-5.9430 \times 10^{-11} p^{3}+1.3189$

$$
\times 10^{-8} p^{2}-1.3155 \times 10^{-6} p+5.1787 \times 10^{-5}
$$

$c_{2}(p)=2.0925 \times 10^{-11} p^{4}-1.2706 \times 10^{-18} p^{3}+2.9240$

$$
\times 10^{-6} p^{2}-3.1192 \times 10^{-4} p+1.4947 \times 10^{-2}
$$

$\lambda_{f}(T, p)=a_{2}(p) T^{2}-b_{2}(p) T+c_{2}(p)$

For $600^{\circ} \mathrm{C} \leq T<800^{\circ} \mathrm{C}$

$$
\begin{aligned}
d_{2}(p)= & 5.1748 \times 10^{-9} p-1.6543 \times 10^{-6} \\
h_{2}(p)= & -4.1957 \times 10^{-12} p^{4}+2.1264 \times 10^{-9} p^{3}-3.742 \\
& \times 10^{-7} p^{2}+2.0819 \times 10^{-5} p+0.00167 \\
\lambda_{f}(T, p)= & d_{2}(p) T+h_{2}(p)
\end{aligned}
$$

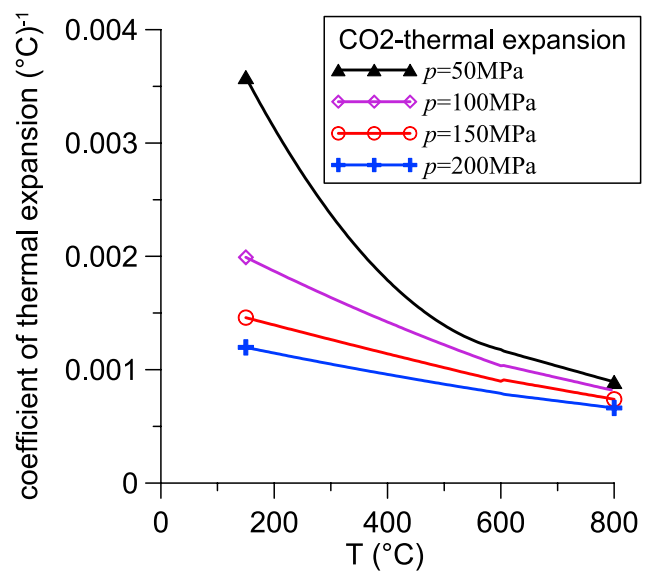

Figure A3. Temperature- and pressure-dependent thermal expansion coefficient of supercritical $\mathrm{CO}_{2}$. 


\section{A5. High Temperatures}

[59] For temperatures greater than $800^{\circ} \mathrm{C}$, the density, the compressibility and the thermal expansion of $\mathrm{CO}_{2}$ can be obtained from the state equation given by Saxena and $\mathrm{Fei}$ [1987] for $\mathrm{p} \geq 100 \mathrm{MPa}$ :

$$
\begin{aligned}
Z= & \left(1-0.5917\left(\frac{T^{c}}{T}\right)^{2}\right)+0.09122 \frac{T^{c} p}{T P^{c}} \\
& -\left[1.4164 \times 10^{-4}\left(\frac{T^{c}}{T}\right)^{2}+2.8349 \times 10^{-16} \ln \frac{T}{T^{c}}\right]\left(\frac{p}{P^{c}}\right)^{2} \\
T^{c}= & 304.14 K, \quad P^{c}=7.38 \mathrm{MPa}
\end{aligned}
$$

[60] Density:

$$
\rho_{f}=\frac{M p}{R T Z(T, p)}, M \text { is the molar mass of } \mathrm{CO}_{2}(44 \mathrm{~g} / \mathrm{mol})
$$

[61] Compressibility:

$$
\beta_{f}=-\frac{p}{Z} \frac{\partial}{\partial p}\left(\frac{Z}{p}\right)
$$

[62] Thermal expansion:

$$
\lambda_{f}=-\frac{1}{T Z} \frac{\partial}{\partial T}(T Z)
$$

[63] Acknowledgments. The authors thank Alexandre Schubnel and Ioannis Vardoulakis for fruitful discussions, Giulio Di Toro and Renaud Toussaint for their constructive comments on the manuscript, and Boris L'vov for his help in understanding the kinetics of carbonate decomposition.

\section{References}

Andrews, D. J. (2002), A fault constitutive relation accounting for thermal pressurization of pore fluid, J. Geophys. Res., 107(B12), 2363, doi:10.1029/2002JB001942

Arai, T., T. Okusawa, and H. Tsukahara (2001), Behavior of gases in the Nojima Fault Zone revealed from the chemical composition and carbon isotope ratio of gases extracted from DPRI $1800 \mathrm{~m}$ drill core, Island Arc, $10(3-4), 430-438$.

Arai, T., H. Tsukahara, and T. Morikiyo (2003), Sealing process with calcite in the Nojima active fault zone revealed from isotope analysis of calcite, J. Geogr., 112(6), 915-925.

Bernabé, Y., U. Mok, and B. Evans (2003), Permeability-porosity relationships in rocks subjected to various evolution processes, Pure Appl. Geophys., 160, 937-960.

Brantut, N., A. Schubnel, J.-N. Rouzaud, F. Brunet, and T. Shimamoto (2008), High-velocity frictional properties of a clay-bearing fault gouge and implications for earthquake mechanics, J. Geophys. Res., 113, B10401, doi:10.1029/2007JB005551.

Brodsky, E. E., and H. Kanamori (2001), Elastohydrodynamic lubrication of faults, J. Geophys. Res., 106(B8), 16,357-16,374.

Boutareaud, S., D. Calugaru, R. Han, O. Fabbri, K. Mizoguchi, A. Tsutsumi, and T. Shimamoto (2008), Clay-clast aggregates: A new textural evidence for seismic fault sliding?, Geophys. Res. Lett., 35, L05302, doi:10.1029/ 2007GL032554

Campanella, R. G., and J. K. Mitchell (1968), Influence of temperature variations on soil behaviour, J. Soil Mech. Found. Div., Am. Soc. Civ. Eng., 94(SM3), 709-734.

Chester, F. M., J. S. Chester, D. L. Kirschner, S. E. Schulz, and J. P. Evans (2004), Structure of large-displacement, strike-slip fault zones, in Rheology and Deformation in the Lithosphere at Continental Margins, edited by G. D. Karner et al., Columbia Univ., New York.

David, C., T.-F. Wong, W. Zhu, and J. Zhang (1994), Laboratory measurement of compaction-induced permeability change in porous rocks: Implications for the generation and maintenance of pore pressure excess in the crust, Pure Appl. Geophys., 143(1-3), 425-456.

Di Toro, G., D. L. Goldsby, and T. E. Tullis (2004), Friction falls towards zero in quartz rock as slip velocity approaches seismic rates., Nature, 427 , $436-439$.

Di Toro, G., S. Nielsen, and G. Pennacchioni (2005), Earthquake rupture dynamics frozen in exhumed ancient faults, Nature, 436, 1009-1012.

Di Toro, G., T. Hirose, S. Nielsen, and T. Shimamoto (2006), Relating highvelocity rock friction experiments to coseismic slip in the presence of melts, in Radiated Energy and the Physics of Faulting, Geophys. Monogr. Ser., vol. 170, edited by R. Abercrombie et al., pp. 121-134, AGU, Washington, D. C.

Dollimore, D., P. Tong, and K. S. Alexander (1996), The kinetic interpretation of the decomposition of calcium carbonate by use of relationships other than the Arrhenius equation, Thermochim. Acta, 282/283, 13-27.

Famin, V., S. Nakashima, A.-M. Boullier, K. Fujimoto, and T. Hirono (2008), Earthquake produce carbon dioxide in crustal faults, Earth Planet. Sci. Lett., 265(3-4), 30,487-30,497.

Flotté, N., D. Sorel, C. Miller, and J. Tensi (2005), Along strike changes in the structural evolution over a brittle detachment fault: Example of the Pleistocene Corinth-Patras rift (Greece), Tectonophysics, 403(1-4), 77-94.

Fujimoto, K., H. Tanaka, N. Tomida, T. Ohtani, and H. Ito (1999), Characterization of fault gouge from GSJ Hirabayashi core samples and implications for the activity of the Nojima fault, in The International Workshop on the Nojima Fault Core and Borehole Data Analysis, edited by H. Ito et al., pp. 103-109, Geol. Surv. of Japan, Tsukuba.

Ghabezloo, S., and J. Sulem (2009), Stress dependent thermal pressurization of a fluid-saturated rock, Rock Mech. Rock Eng., 42, 1-24.

Han, R., T. Shimamoto, T. Hirose, J.-H. Ree, and J. Ando (2007), Ultralow friction of carbonate faults caused by thermal decomposition, Science, $316,878-881$.

Heard, H. C., and W. W. Rubey (1966), Tectonic implications of gypsum dehydration, Geol. Soc. Am. Bull., 77, 741-760.

Heermance, R., Z. K. Shipton, and J. P. Evans (2003), Fault Structure Control on Fault Slip and Ground Motion during the 1999 Rupture of the Chelungpu Fault, Bull. Seismol. Soc. Am., 93, 1034-1050.

Hirono, T., et al. (2006), Evidence of frictional melting from disk-shaped black material, discovered within the Taiwan Chelungpu fault system, Geophys. Res. Lett., 33, L19311, doi:10.1029/2006GL027329.

Hirono, T., et al. (2007), A chemical kinetic approach to estimate dynamic shear stress during the 1999 Taiwan Chi-Chi earthquake, Geophys. Res. Lett., 34, L19308, doi:10.1029/2007GL030743.

Italiano, F., G. Martinelli, and P. Plescia (2008), CO2 degassing over seismic areas: The role of mechanochemical production at the study case of Central Apennines, Pure Appl. Geophys., 165, 75-94.

Kanamori, H., and E. Brodsky (2004), Physics of Earthquakes, Rep. Prog. Phys., 67(8), 1429-1496.

Ko, S.-C., D. L. Olgaard, and U. Briegel (1995), The transition from weakening to strengthening in dehydrating gypsum: Evolution of excess pore pressure, Geophys. Res. Lett., 22(9), 1009-1012.

Lachenbruch, A. H. (1980), Frictional heating, fluid pressure and the resistance to fault motion, J. Geophys. Res., 85(B11), 6097-6112.

Lachenbruch, A. H., and J. H. Sass (1980), Heat flow and energetics of the San Andreas Fault Zone, J. Geophys. Res., 85(11), 6185-6223.

Lee, T. C., and P. T. Delaney (1987), Frictional heating and pore pressure rise due to a fault slip, Geophys. J. R. Astron. Soc., 88(3), 569-591.

Lewicki, J. L., and S. L. Brantley (2000), $\mathrm{CO}_{2}$ degassing along the San Andreas fault, Parkfield, California, Geophys. Res. Lett., 27(1), 5-8.

Lewicki, J. L., W. C. Evans, G. E. Hilley, M. L. Sorey, J. D. Rogie, and S. L. Brantley (2003), Shallow soil $\mathrm{CO}_{2}$ flow along the San Andreas and Calaveras Faults, California, J. Geophys. Res., 108(B4), 2187, doi:10.1029/2002JB002141

Lin, A., N. Tanaka, S. Uda, and M. Satish-Kumar (2003), Repeated coseismic infiltration of meteoric and seawater into deep fault zones: A case study of the Nojima fault zone, Japan, Chem. Geol., 202(1-2), 139-153.

L'vov, B. V. (2002), Mechanism and kinetics of thermal decomposition of carbonates, Thermochim. Acta, 386, 1-16.

L'vov, B. V. (2007), Thermal Decomposition of Solids and Melts, Springer, Netherlands, doi:10.1007/978-1-4020-5672-7.

L'vov, B. V., and V. L. Ugolkov (2004), Peculiarities of $\mathrm{CaCO}_{3}, \mathrm{SrCO}_{3}$ and $\mathrm{BaCO}_{3}$ decomposition in $\mathrm{CO}_{2}$ as a proof of their primary dissociative evaporation, Thermochim. Acta, 410, 47-55.

Mase, C. W., and L. Smith (1985), Pore-fluid pressures and frictional heating on a fault surface, Pure Appl. Geophys., 122, 583-607.

McKenzie, D., and J. N. Brune (1972), Melting on fault planes during large earthquakes, Geophys. J. R. Astronom. Soc., 29, 65-78.

Melosh, H. J. (1996), Dynamic weakening of faults by acoustic fluidization, Nature, 397, 601-606. 
Ohtani, T., K. Fujimoto, H. Ito, H. Tanaka, N. Tomida, and T. Higuchi (2000), Fault rocks and past to recent fluid characteristics from the borehole survey of the Nojima fault ruptured in the 1995 Kobe earthquake, Southwest Japan, J. Geophys. Res., 106(B7), 16,161-16,171.

Olgaard, D. L., S. C. Ko, and T.-F. Wong (1995), Deformation and pore pressure in dehydrating gypsum under transiently drained conditions, Tectonophysics, 245, 237-248.

Otsuki, K., N. Monzawa, and T. Nagase (2003), Fluidization and melting of fault gouge during seismic slip: Identification in the Nojima fault zone and implications for focal earthquake mechanisms, J. Geophys. Res., 108(B4), 2192, doi:10.1029/2001JB001711.

Palciauskas, V. V., and P. A. Domenico (1982), Characterization of drained and undrained response of thermally loaded repository rocks, Water Resour. Res., 18(2), 281-290.

Pizzino, L., F. Quattrochi, D. Cinti, and G. Galli (2004), Fluid geochemistry along the Eliki and Aigion seismogenic segments (Gulf of Corinth Greece), C. R. Geosci., 336, 367-374.

Raleigh, C. B., and M. S. Paterson (1965), Experimental deformation of serpentinite and its tectonic implications, J. Geophys. Res., 70(16), $3965-3985$

Rempel, A. W., and J. R. Rice (2006), Thermal pressurization and onset of melting in fault zones, J. Geophys. Res., 111, B09314, doi:10.1029/ 2006JB004314.

Rice, J. R. (2005), Large scale localization: Thermal weakening of faults during seismic slip, in Thematic Meeting on Instabilities, Bifurcations, Localization, 24-25 February, Institut Poincaré, Paris, France.

Rice, J. R. (2006), Heating and weakening of faults during earthquake slip, J. Geophys. Res., 111, B05311, doi:10.1029/2005JB004006.

Rosakis, P., A. J. Rosakis, G. Ravichandran, and J. Hodowany (2000), A thermodynamic internal variable model for the partition of plastic work into heat and stored energy in metals, J. Mech. Phys. Solids, 48, 581607.

Sato, T., and M. Takahashi (1997), Geochemical changes in anomalously discharged groundwater in Awaji Island after the 1995 Kobe earthquake, Chikyukagaku, 31, 89-98.

Saxena, S. K., and Y. Fei (1987), Fluids at crustal pressures and temperatures: 1. Pure species, Contrib. Mineral. Petrol., 95, 370-375.

Sibson, R. H. (1973), Interactions between temperature and pore fluid pressure during earthquake faulting - a mechanism for partial or total stress relief, Nat. Phys. Sci., 243, 66-68.

Sibson, R. H. (1975), Generation of pseudotachylyte by ancient seismic faulting, Geophys. J. Int., 43(3), 775.

Sibson, R. H., and V. Toy (2006), The habitat of fault-generated pseudotachylyte: Presence vs. absence of friction melt, in Radiated Energy and the Physics of Faulting, Geophys. Monogr. Ser., vol. 170, edited by R. Abercrombie et al., pp. 153-166, AGU, Washington, D. C.

Sulem, J., I. Vardoulakis, H. Ouffroukh, M. Boulon, and J. Hans (2004), Experimental characterization of the thermo-poro-mechanical properties of the Aegion fault gouge, C. R. Geosci., 336(4-5), 455-466.

Sulem, J., I. Vardoulakis, H. Ouffroukh, and V. Perdikatsis (2005), Thermoporo-mechanical properties of the Aigion fault clayey gouge - application to the analysis of shear heating and fluid pressurization, Soils Found., 45(2), 97-108.

Sulem, J., P. Lazar, and I. Vardoulakis (2007), Thermo-poro-mechanical properties of Clayey Gouge and application to rapid fault shearing, Int. J. Numer. Anal. Methods Geomech., 31(3), 523-540.

Sultan, N. (1997), Etude du comportement thermo-mécanique de l'argile de Boom: Expériences et modélisation, Ph.D. thesis, Ecole Nationale des Ponts et Chaussées, France.

Tanaka, H., K. Fujimoto, T. Ohtani, and H. Ito (2001), Structural and chemical characterization of shear zones in the freshly activated Nojima fault, Awaji Island, southwest Japan, J. Geophys. Res., 106(B5), 87898810

Ueda, A., A. Kawabata, K. Fujimoto, H. Tanaka, N. Tomida, T. Ohtani, and H. Ito (1999), Isotopic study of carbonates in Nojima fault cores, in The International Workshop on the Nojima Fault Core and Borehole Data Analysis, edited by H. Ito et al., pp. 127-132, Geol. Surv. of Japan, Tsukuba.

Vardoulakis, I. (2002), Dynamic thermo-poro-mechanical analysis of catastrophic landslides, Géotechnique, 52(3), 157-171.

Veveakis, E., I. Vardoulakis, and G. Di Toro (2007), Thermoporomechanics of creeping landslides: The 1963 Vaiont slide, northern Italy, J. Geophys. Res., 112, F03026, doi:10.1029/2006JF000702.

Wibberley, C., and T. Shimamoto (2005), Earthquake slip weakening and asperities explained by thermal pressurization, Nature, 426(4), 689-692.

Wong, T.-F., S.-C. Ko, and D. L. Olgaard (1997), Generation and maintenance of pore pressure excess in a dehydrating system: 2 . Theoretical analysis, J. Geophys. Res., 102(B1), 841-852.

V. Famin, Géosciences Réunion (LSTUR), Université de la Réunion, Institut de Physique du Globe de Paris/CNRS, UMR 7154, 15 avenue René Cassin, BP 7151, 97715 Saint Denis messag, Cedex 9, La Réunion, France.

J. Sulem, CERMES, UR Navier, Ecole des Ponts ParisTech, Universite Paris-Est, 6, 8 Avenue Blaise Pascal, Cité Descartes, Champs sur Marne, F-77455 Marne-la Vallée Cedex 2, France. (sulem@cermes.enpc.fr) 